\title{
Distinct neuronal subtypes of the lateral habenula differentially target ventral tegmental area dopamine neurons
}

Michael L. Wallace ${ }^{1}$, Kee Wui Huang ${ }^{1}$, Daniel Hochbaum ${ }^{1}$, Minsuk Hyun ${ }^{1}$, Gianna

Radeljic $^{1}$, and Bernardo L. Sabatini ${ }^{1}$

${ }^{1}$ Howard Hughes Medical Institute, Department of Neurobiology, Harvard Medical

School, Boston, MA 02115, USA.

Correspondence: bsabatini@hms.harvard.edu 


\section{ABSTRACT}

2 The lateral habenula $(\mathrm{LHb})$ is an epithalamic brain structure critical for processing and

3 adapting to negative action outcomes. However, despite the importance of LHb to

4 behavior and the clear anatomical and molecular diversity of LHb neurons, the neuron

5 types of the habenula remain unknown. Here we use high-throughput single-cell

6 transcriptional profiling, monosynaptic retrograde tracing, and multiplexed FISH to

7 characterize the cells of the mouse habenula. We find 5 subtypes of neurons in the

8 medial habenula $(\mathrm{MHb})$ that are organized into anatomical subregions. In the LHb we

9 describe 4 neuronal subtypes and show that they differentially target dopaminergic and

10 GABAergic cells in the ventral tegmental area (VTA). These data provide a valuable

11 resource for future study of habenular function and dysfunction and demonstrate

12 neuronal subtype specificity in the LHb-VTA circuit.

\section{INTRODUCTION}

The habenula is an epithalamic structure divided into medial $(\mathrm{MHb})$ and lateral $(\mathrm{LHb})$ subregions that receives diverse input from the basal ganglia, frontal cortex, basal

17 forebrain, hypothalamus and other regions involved in processing both sensory

18 information and internal state (Herkenham and Nauta, 1977; Yetnikoff et al., 2015).

19 Two main targets of the LHb output are major monoaminergic structures in the brain,

20 the ventral tegmental area (VTA) and raphe nuclei (dorsal (DRN) and medial (MRN)),

21 whereas the $\mathrm{MHb}$ targets the interpeduncular nucleus (Herkenham and Nauta, 1979).

22 Due to its dual effects on dopamine and serotonin producing neurons, LHb has been

23 proposed to contribute to the neurobiological underpinnings of depression and addiction

24 (Li et al., 2011, 2013; Maroteaux and Mameli, 2012; Meye et al., 2016). Furthermore,

25 the LHb has been implicated in a wide range of functions and behaviors including

26 reward prediction error, aversion, cognition, and adaptive decision making (Hikosaka,

27 2010; Matsumoto and Hikosaka, 2007; Mizumori and Baker, 2017; Proulx et al., 2014;

28 Tian and Uchida, 2015; Wang et al., 2017).

29 The effects of $\mathrm{LHb}$ on each downstream structure and its contribution to different

30 behaviors are likely carried out by distinct populations of neurons. In addition, the $\mathrm{LHb}$

31 may, at the macroscopic level, consist of distinct sub-domains with differential 
32 contributions to limbic and motor functions (Zahm and Root, 2017). Further, many

33 studies suggest that habenular neurons show differences in gene expression across

34 hemispheres (Concha and Wilson, 2001; Pandey et al., 2018), projection targets (Quina

35 et al., 2014, 2015), and anatomical location (Gonçalves et al., 2012). Nevertheless, the

36 systematic relationship between molecular profiles, projections patterns, and anatomical

37 organization of neurons in the LHb is unknown.

$38 \quad$ Here we provide a comprehensive description of the neuronal subtypes in the

39 LHb based on single-cell transcriptional profiling, multiplexed fluorescent in situ

40 hybridization (FISH), and cell type specific monosynaptic retrograde tracing.

41 Furthermore, as the $\mathrm{MHb}$ was included in our dissections, we also provide a molecular

42 description of this nucleus. We find that the MHb has five, and $\mathrm{LHb}$ has four,

43 transcriptionally-defined neuronal subtypes. Interestingly, the $\mathrm{HbX}$ subtype, which lies

44 at the border between the $\mathrm{MHb}$ and $\mathrm{LHb}$, is more transcriptionally similar to other $\mathrm{LHb}$

45 subtypes than $\mathrm{MHb}$ subtypes. We find that the four $\mathrm{LHb}$ neuronal subtypes are distinct

46 and monosynaptic retrograde tracing revealed that they differentially target the

47 dopaminergic and GABAergic neurons of the VTA. Furthermore, we find the LHb is

48 organized into subregions defined by these transcriptionally discriminable neuronal

49 subtypes. Together we identify previously unknown neuronal heterogeneity in the

50 habenula and reveal that different neuronal classes have target biases in the VTA.

52 RESULTS

53 Cell type composition of the habenula by transcriptomic profiling

54 To examine cellular heterogeneity in the habenula, we performed high-throughput

55 single-cell transcriptional profiling ("InDrop”) (Klein et al., 2015). Cell suspensions from

56 the habenula were generated from acute, microdissected brain slices from adult mice

57 (Figure 1A), producing 25,289 single-cell transcriptomes (SCTs). Excluding SCTs with

$58<200$ genes, 500 UMls, or $>10 \%$ mitochondrial genes resulted in 7,506 SCTs that were

59 further analyzed. This subset had median counts of $2593 \mathrm{UMIs}$ ( $\min =501$, $\max =$

$6017787, I Q R=3986)$ and 349 genes $(\min =302, \max =5276, I Q R=1733$ ) per cell

61 (Figure S1C). Subsequent analysis of gene expression patterns by principal

62 components (PC) analysis and shared-nearest-neighbors (Satija et al., 2015) resulted in 
6312 cellular clusters (Figure 1B, see Materials and Methods for details on sequential 64 clustering). Major cell classes (i.e. neurons, astrocytes, microglia, etc...) within these

65 clusters were identified by expression of cell-type specific gene combinations that were 66 extensive cross-referenced with published datasets (Saunders et al., 2018; Zeisel et al., 67 2018) (Figure 1B-C). In contrast to other species (Pandey et al., 2018), no major

68 transcriptional differences were observed (Figure S1A-B) across left and right

69 hemispheres; therefore, cells from both hemispheres were pooled for analysis. The 70 majority of the cells in the dataset were neurons (53\%) and we focused our analysis on 71 these clusters for the remainder of the study.

72 Neurons ( $n=3,930$ cells), identified by expression of genes required for chemical 73 synaptic transmission such as Snap25, Syp, and Syt4, clustered into 2 main classes

74 (Figure 1B-C). We examined if these 2 neuronal clusters could be spatially 75 distinguished using digital in situ hybridization (ISH) analysis (Allen Brain Atlas, (Lein et 76 al., 2007)) of differentially expressed genes (Finak et al., 2015). The larger cluster of 77 neurons ( $n=3,370$ cells) expressed Tac2 and corresponds to the MHb (Figure 2), 78 whereas the smaller cluster ( $\mathrm{n}=560$ cells) expressed Gap43 and corresponds to the $79 \mathrm{LHb}$ (Figure 3).

Differential gene expression reveals the spatial organization of $\mathrm{MHb}$ neuron subtypes

83 Analysis of $\mathrm{MHb}$ neurons revealed that they could be divided into 8 clusters (Figure

84 S2A). However, 3 clusters were clearly distinguished by high expression of activity-

85 dependent genes (ADGs) (Figure S2B), suggesting that they might simply reflect

86 neurons of other clusters that had been recently strongly activated. Indeed, regressing

87 out the PC containing a large number of ADGs (Figure S2E-F) caused these 3 high ADGs clusters to merge with other MHb clusters (Figure S2C-D), leaving 5 distinct

89 subtypes of $\mathrm{MHb}$ neurons.

We constructed a cluster dendrogram using the averaged cluster gene

91 expression to examine the transcriptional differences between these subtypes (Figure

92 2D). In general, subtypes of $\mathrm{MHb}$ neurons were divided by genes that were involved in

93 the synthesis and packaging of different neurotransmitters and neuropeptides. All MHb 
94 neurons expressed high levels of S/c17a6 and S/c17a7, the genes encoding vesicular

95 glutamate transporters 1 and 2, and Tac2 suggesting that all $\mathrm{MHb}$ neurons are

96 glutamatergic and produce the neuropeptide Neurokinin B (Figure 2D, S4A). Two of the

97 five clusters also expressed Slc18a3 and Chat (not shown), the vesicular transporter

98 and biosynthetic enzyme for acetylcholine, respectively, indicating that these neurons

99 may co-release glutamate and acetylcholine (Figure S4A), as has been described in

100 several studies (Ren et al., 2011; Soria-Gómez et al., 2015). Interestingly, no MHb

101 neurons expressed significant levels of the canonical GABA handling genes SIc32a1,

102 Gad1, or Slc18a2 (although Gad2 was expressed at low levels in all subtypes);

103 therefore, they are unlikely to release GABA.

104 To examine the spatial distribution of $\mathrm{MHb}$ neuron subtypes we cross referenced

105 their differentially expressed genes (DEGs) with the Allen Mouse Brain Atlas of ISH

106 hybridization data (Table 3) (Lein et al., 2007). Generally, we found that individual

107 DEGs for particular MHb subtypes consistently mapped onto discrete regions in the

$108 \mathrm{MHb}$ (Figure 2C, S3). Also, DEGs for MHb neurons were rarely DEGs for $\mathrm{LHb}$ neurons

109 (Figure S4A). This permitted classification of transcriptionally defined MHb subtypes to

110 particular subregions of MHb (Figure 2D, S7). MHb neurons divided along the

111 dorsal/ventral axis with a third lateral (enriched for genes Sema3d, Calb1, and Spon1)

112 subtype (Figure 2C-D, S3C-E). Ventral groups could be further subdivided into two

113 distinct subtypes, the "ventral two thirds" of the MHb (enriched for Lmo3) and the

114 "ventrolateral" MHb (enriched for genes Esam and Slc18a3). Gene expression patterns

115 indicated that it is possible that neurons from these two subtypes were partially

116 intermingled and did not form a defined border (Figure 2C, S3A-B). The rest of the MHb

117 could be subdivided into the "dorsal" (enriched for genes Col16a1, Wif1, and Adcyap1)

118 and "superior" (enriched for genes Cck and Avi) subtypes. These two groups split along

119 a medial/lateral axis with the "dorsal" being more laterally located than the "superior"

120 (Figure 2C-D, S3F-I) (Wagner et al., 2016, 2014).

122 Genetic distinction of four LHb neuron subtypes

123 Gap43 is highly expressed in the LHb and along with several other genes (Htr2c,

124 Pcdh10, Gabra1, and Syn2) distinguishes neurons of this region from those of 
125 neighboring $\mathrm{MHb}$ (Figure 3A-B, S4A). Unlike for MHb neurons, we did not detect

126 significant elevation of ADGs in LHb neurons. We found 4 distinct clusters of neurons in

127 LHb which, again unlike MHb, did not have distinct expression profiles of genes

128 involved in the synthesis and packaging of different typical fast neurotransmitters (e.g.

129 glutamate, GABA, acetylcholine) - all LHb neurons expressed high levels of S/c17a6

130 and very low levels of S/c32a1, suggesting that they are glutamatergic.

131 Subdivisions of the lateral habenula based on topographic, morphological and

132 cytochemical criteria have been described in rat (Andres et al., 1999) and mouse

133 (Wagner et al., 2016, 2014) and are used here to describe the patterns of DEGs

134 extracted from our single-cell dataset (see terms in quotes below). We examined the

135 spatial distribution of LHb neuron subtypes by cross referencing their differentially

136 expressed genes (DEGs) with the Allen Mouse Brain Atlas of ISH data (Lein et al.,

137 2007). We found that DEGs showed 4 distinct, but consistent patterns that aligned with

138 their subclusters (Figure 3C-D, S8). These consisted of 1) a cluster that showed high

139 expression of DEGs in both the "lateral oval" and "central medial" subdivision, we

140 named this the oval/medial subdivision; 2) a cluster that showed high expression of

141 DEGs in the "marginal subdivision of the medial division of the LHb", we called this the

142 marginal subdivision; 3 ) a cluster that showed high expression of DEGs in the "lateral"

143 subdivision (but avoiding expression in the "lateral oval"), we also called this the lateral

144 subdivision; and 4) a cluster that showed high expression of DEGs in the subdivision

145 defined as " $\mathrm{HbX}$ " lying on the dorsal border between $\mathrm{MHb}$ and $\mathrm{LHb}$, we also refer to this

146 as the $H b X$ subdivision (Figure $3 C$ ) (Wagner et al., 2016, 2014). Interestingly, the $H b X$

147 region is more closely related in its gene expression to other LHb clusters than to any

148 clusters in the $\mathrm{MHb}$; therefore it is more similar to $\mathrm{LHb}$ neurons than previously

149 recognized (Figure 3D) (Wagner et al., 2016).

150 We performed multiplexed FISH to confirm that the 4 transcriptionally-defined

151 clusters of $\mathrm{LHb}$ neurons were distinct and anatomically organized within the $\mathrm{LHb}$. We

152 chose 4 highly expressed DEGs (Chrm3, Vgf, Gpr151, and Sst) and examined gene

153 expression levels in individual neurons (Figure 4). As predicted by the single cell

154 sequencing, the chosen genes generally expressed in different cells, confirming that

155 they defined molecularly distinct neuronal subtypes (Figure 4). An exception to this 
156 general rule, but consistent with the predictions of single cell sequencing, individual 157 neurons in the HbX expressed both Sst and Gpr151 (Figure 4D). Additionally, when

158 strongly expressed, Chrm3 and Vgf were found in different cells, but they were

159 occasionally co-expressed in neurons that had relatively low levels of both genes

160 (Figure 4A).

The chosen genes are largely expressed in non-overlapping patterns at the

162 macroscopic level, confirming the organization of LHb into molecularly-defined

163 subregions (Figure 4, S7). Nevertheless, cells from a subtype did intermingle with cells

164 of another group and sharply defined borders between LHb subregions were not

165 observed (e.g. Figure 4C). Therefore, diagrams of gene expression (Figure 4) illustrate

166 where gene expression is greatest or where cells expressing the gene are most

167 numerous and not that gene expression is perfectly restricted to a particular subregion.

\section{LHb neuron subtypes differentially target VTA GABAergic and dopaminergic}

171 The LHb projects via the fasciculus retroflexus to the ventral tegmental area (VTA),

172 rostromedial tegmental area (RMTg), and median/dorsal raphe (Herkenham and Nauta,

173 1977). The VTA consists of a large and diverse population of dopamine neurons, as

174 well as smaller populations of purely GABAergic, purely glutamatergic, and

175 GABA/glutamate coreleasing neurons. Both GABAergic and dopaminergic VTA neurons

176 receive input from the LHb (Beier et al., 2015; Lammel et al., 2012; Morales and

177 Margolis, 2017; Watabe-Uchida et al., 2012) but it is unknown if these arise from

178 molecularly distinct $\mathrm{LHb}$ neurons. We tested if there was connectivity specificity

179 between LHb and VTA neuronal subtypes using rabies virus based monosynaptic

180 retrograde tracing (Wickersham et al., 2007). To examine LHb input to VTA GABAergic

181 neurons we injected Cre-dependent TVA-mCherry into the VTA of a VGAT-IRES-Cre

182 mouse to restrict initial rabies virus infection to GABAergic neurons. We also coinjected

183 a Cre-dependent AAV encoding the rabies glycoprotein (RVG) to allow for retrograde

184 monosynaptic transfer of G-deleted, pseudotyped, rabies virus (EnvA-RbV-GFP). As

185 only neurons with Cre will express RVG, GFP-labeled neurons in other regions are

186 putatively presynaptic to GFP+/RVG+ VTA neurons (see Figure S6E for controls for 
187 specificity of EnvA-RbV-GFP infection). FISH in the VTA revealed that $\sim 30 \%$ of "starter 188 cells" (neurons that were GFP+ and Cre+), coexpressed Slc17a6 indicating they are 189 likely GABA/glutamate coreleasing neurons (Figure S6C) (Root et al., 2014). The 190 majority of the remaining $70 \%$ of "starter cells" are purely GABAergic (Figure S6C-D). Using FISH we found retrogradely labeled neurons, marked by expression of 193 Gpr151, and Sst) (Figure 5C-D, S5A). The majority of retrogradely labeled LHb 194 neurons were found in the lateral and oval/medial subtypes in roughly equal proportions (mean $\pm S E M: ~ 48 \pm 0.5 \%$ Gpr151+ and $41 \pm 0.6 \%$ Chrm3+, respectively) (Figure 5D). A

196 much smaller proportion was found in the marginal subtype $\left(10 \pm 1 \% V g f_{+}\right)$, and very few $197 \mathrm{HbX}$ neurons $(2 \pm 1 \%$ Sst+) were retrogradely labeled.

To examine LHb input to VTA dopaminergic neurons we performed monosynaptic retrograde tracing using the same series of viral injections in DAT-IRES-

200 Cre mice (Figure 5A). FISH in the VTA revealed that $~ 91 \%$ of "starter cells" (neurons 201 that were GFP+ and Cre+), coexpressed Slc6a3 (dopamine transporter, DAT) indicating 202 they are dopaminergic neurons (Figure S6D) (Morales and Margolis, 2017; Tritsch et 203 al., 2012). The remaining $9 \%$ of starter cells express varying levels of Slc32a1 (VGAT) 204 indicating low levels of starter cell overlap with the experiments done in the VGAT205 IRES-Cre line (Figure S6D). We performed FISH on retrogradely labeled neurons in the $206 \mathrm{LHb}$ and found that a much larger proportion of retrogradely labeled neurons in the 207 oval/medial and marginal subtypes (61 $\pm 2 \%$ Chrm3+ and $20 \pm 1 \%$ Vgft, respectively) in 208 the DAT-IRES-Cre than the VGAT-IRES-Cre line (Figure 5C-D, S5B). Consequently, a 209 smaller proportion of neurons in the lateral subtype were labeled (10 $\pm 0.4 \%$ Gpr151+) 210 and almost no neurons in the $\mathrm{HbX}$ subregion were labeled $(0.7 \pm 0.5 \% \mathrm{Sst}+)$ (Figure 5D, 211 S5B). Together these data suggest that both VTA GABAergic and dopaminergic 212 neurons can receive input from all 4 subtypes of LHb neuron. However, VTA 213 dopaminergic neurons receive the largest proportion of their $\mathrm{LHb}$ input from the $214 \mathrm{oval} /$ medial LHb subtype, whereas VTA GABAergic neurons receive equal levels of 215 input from both the oval/medial and lateral LHb subtypes (Table 6). 
217 All LHb neuron subtypes project to the DRN in proportions similar to VTA

\section{8 dopamine neurons}

219 LHb neurons heavily innervate the dorsal and median raphe nuclei (DRN/MRN) and

220 modulate serotonergic output throughout the brain (Zhao et al., 2015; Zhou et al., 2017).

221 To examine the LHb subtypes that project to the DRN, we injected a non-pseudotyped

222 rabies virus (RbV-GFP) into this area and performed FISH in the LHb for subtype

223 enriched genes (Figure 5B-C). Similar to dopaminergic VTA neurons, the DRN

224 received the largest proportion of its LHb input from the oval/medial subtype (51 $\pm 2 \%$

225 Chrm3+) (Figure 5C-D, S5C). The DRN also received minor inputs from the lateral

$226(16 \pm 5 \%$ Gpr151+), marginal $(28 \pm 5 \% \mathrm{Vgf}+)$, and $\mathrm{HbX}(1 \pm 0.5 \%$ Sst+) regions (Figure 5D,

227 S5C). Overall, the proportions of input to the DRN arising from different LHb subtypes

228 were more similar to those to VTA dopamine neurons than those to VTA GABA neurons

229 (Table 6).

\section{DISCUSSION}

232 We performed transcriptional and anatomical analyses of the habenula, a crucial circuit

233 node that modifies brain-wide dopamine and serotonin levels through its connections to

234 the VTA and DRN (Proulx et al., 2014; Tian and Uchida, 2015; Zhao et al., 2015).

235 Using large-scale single cell transcriptional profiling, we classify $\mathrm{MHb}$ and $\mathrm{LHb}$ neurons

236 into five and four major neurons types, respectively, and show that each class has a

237 distinct gene expression pattern. The four $\mathrm{LHb}$ populations were confirmed to be non-

238 overlapping at the single-cell level by FISH. Monosynaptic retrograde tracing revealed

239 that GABAergic VTA neurons receive equal input from the oval/medial and lateral LHb

240 neuronal subtypes, whereas dopaminergic VTA neurons receive input primarily from the

$241 \mathrm{oval} /$ medial LHb subtype. Finally, neurons of the DRN receive input from the LHb in

242 roughly similar proportions to dopaminergic VTA neurons.

244 Anatomical distribution of MHb neuronal subtypes

245 Recent studies have identified and delineated the subnuclei of the mouse MHb using

246 morphological, topographic and cytochemical criteria (Wagner et al., 2016, 2014).

247 Using single-cell transcriptional profiling, we show that $\mathrm{MHb}$ neurons can be categorized 
248 into subtypes based on differential gene expression. Furthermore, the spatial

249 distribution of these transcripts allowed us to ascribe an anatomical location to each

250 subtype. The anatomical location of these subtypes largely agree with previously

251 defined $\mathrm{MHb}$ subnuclei and we have used the same nomenclature when possible

252 (Figure S7) (Wagner et al., 2016).

253 The two ventral subtypes of the $\mathrm{MHb}$ coexpressed transcripts for glutamate and

254 ACh neurotransmission (Figure S4). Our data suggest these two ventral subtypes can

255 be differentially targeted with intersectional approaches, as genes such as $L m o 3$ and

256 Esam are preferentially expressed in one subtype (Figure 2D, S4). Previous studies

257 indicate that $\mathrm{MHb}$ neurons that release glutamate and $\mathrm{ACh}$ target the medial

258 interpeduncular nucleus (IPN) (Ren et al., 2011) and are involved in the formation of

259 aversive memories (Soria-Gómez et al., 2015). However, whether one or both of the

260 transcriptionally-defined subtypes are involved in this process is unknown.

Additionally, cholinergic transmission in $\mathrm{MHb}$ has also been implicated in nicotine

262 addiction as $\mathrm{MHb}$ neurons not only release $\mathrm{ACh}$, but express an array of nicotinic

263 acetylcholine receptor subunits (nAChRs, such as Chrna3 and Chrnb3; Figure S3 and

264 Table 4) (Fowler et al., 2011; Shih et al., 2014). Similar to its involvement in aversive

265 memories, MHb likely plays an important role in mediating the unpleasant symptoms

266 associated with nicotine withdrawal (Zhao-Shea et al., 2013). Our data provide a

267 comprehensive view of all $\mathrm{nAChR}$ and $\mathrm{mAChR}$ transcripts expressed in both $\mathrm{MHb}$ and

$268 \mathrm{LHb}$ providing a resource for the development of new therapeutic targets for the

269 treatment of addiction (Table 4) (D'Souza, 2016; Zuo et al., 2016).

$270 \quad$ Few studies have examined the function of the dorsal (enriched for genes

271 Col16a1, Wif1, and Adcyap1) and superior (enriched for genes Cck, and Avil) MHb.

272 These neurons were known to express high levels of Tac1 (the gene that produces the

273 neuropeptide substance P), consistent with our single-cell sequencing data (Figure S3J,

274 Table 4) and target the lateral IPN (Hsu et al., 2016). Their activation may be

275 reinforcing (Hsu et al., 2014), but detailed analysis of their function and neurotransmitter

276 release has not been examined. 


\section{LHb neuronal subtypes}

279 We referenced recent studies on LHb subnuclei to create a map (Figure S7) of LHb

280 based on DEGs extracted from single-cell transcriptional profiling (Wagner et al., 2016,

281 2014). Overall, our map largely agrees with previous work and adds many key

282 observations into the organization and cellular and molecular diversity of the LHb. In

283 addition to providing multiple genetic handles that can be used in future studies to target

284 LHb neuron subtypes, our study reveals the a wide range of GPCRs (such as Htr2c,

285 Htr5b, Sstr2, Gpr151; see Table 4) expressed in LHb neurons that could be targeted for

286 treatment of diseases known to effect LHb function such as depression, anxiety, and

287 addiction (Lecca et al., 2014; Proulx et al., 2014). In contrast to some reports (Zhang et

288 al., 2018), we did not find evidence of GABAergic neurons in the LHb (or MHb).

289 Although Gad2 and Slc6a1, which encode a GABA synthetic enzyme and GABA

290 transporter, respectively, were present at low levels in all LHb clusters we did not find

291 expression of Slc32a1 or Slc18a2, which are required for vesicular loading of GABA

292 (Table 4). This is in agreement with recently published results demonstrating that Gad2

293 expression is a poor discriminator for inhibitory (GABAergic) neurons (Moffitt et al.,

294 2018). Therefore, either LHb GABAergic cells are rare enough to be missed in the

295 single cell transcriptomes, or the habenula is devoid of GABAergic neurons.

We used Gpr151 expression to mark the lateral, and to a lesser extent $\mathrm{HbX}$,

297 regions of the LHb. The Gpr151+ neurons of the lateral LHb are the most well-studied

298 neuronal subtype in the LHb and they receive major input from the lateral preoptic area,

299 lateral hypothalamus, entopeduncular nucleus (EP), basal nucleus of the stria

300 terminalis, and the nucleus of the diagonal band (Broms et al., 2017). These neurons

301 also receive a minor input from the VTA, and are positioned to receive GABA/glutamate

302 coreleasing input from both the EP and VTA (Root et al., 2014; Wallace et al., 2017).

303 Gpr151+ axons, likely arriving from the LHb, heavily innervate the RMTg and central

304 and median raphe nucleus, but not the VTA (Broms et al., 2015). Our retrograde

305 tracing studies from VTA neurons show that Gpr151+ neurons tend to avoid

306 dopaminergic VTA neurons, but heavily innervated the intermingled GABAergic neurons

307 in this brain region (Figure 5). VTA GABAergic interneurons are functionally similar to

308 inhibitory RMTg neurons (both populations inhibit VTA dopaminergic neurons (Cohen et 
al., 2012; Ji and Shepard, 2007)), consistent with our results that both are innervated by lateral LHb. Furthermore, the lateral LHb is likely the major LHb subtype to translate aversive signals to VTA GABAergic neurons which become active following reward

312 omission due to increased LHb input (Tian and Uchida, 2015). Overall, these cells are

313 positioned to translate signals arriving from EP to downstream midbrain structures

314 involved in both dopamine and serotonin signaling.

315 The oval/medial subregion of the LHb expresses high levels of Chrm3. Our

316 previous studies indicate that this subtype is positioned to receive purely glutamatergic

317 input from Pvalb+/S/c16a7+EP neurons that specifically target the lateral oval nucleus

318 of the LHb (Wallace et al., 2017). Additionally, GABA/glutamate coreleasing EP

319 neurons target the lateral oval (as well as the neighboring Gpr151+ lateral LHb)

320 providing overlapping, but differential EP input to this subregion (Wallace et al., 2017).

321 Electrophysiological analysis has also shown preferential input from EP to the lateral

$322 \mathrm{LHb}$, specifically, to the neurons that project to RMTg (Meye et al., 2016).

The LHb primarily targets meso-prefrontal VTA dopamine neurons while avoiding other (mesolimbic and substantia nigra) dopamine neurons (Lammel et al., 2012). We were surprised to find that the majority of LHb neurons that projected to VTA dopamine neurons expressed Chrm3, a gene enriched in the oval/medial subregion, as previous retrograde tracing studies suggest that the marginal portion of the $\mathrm{LHb}$ projects heavily to the VTA ((Meye et al., 2016), but also see (Petzel et al., 2017; Quina et al., 2014)). Additional studies suggest that LHb neurons that target the VTA dopamine neurons may be distinct from those that target the RMTg; therefore, two populations of Chrm3+ $\mathrm{LHb}$ neurons with different synaptic targets may exist (Lammel et al., 2012; Li et al., 2011; Maroteaux and Mameli, 2012). Additional genetic heterogeneity between Chrm3+ oval and medial subdivisions could be further resolved with higher resolution sequencing 334 methods (Bakken et al., 2018; Tasic et al., 2018). Nevertheless, our data show that VTA dopamine, and VTA GABAergic neurons are positioned to receive quite different synaptic input from the $\mathrm{LHb}$ due to their differential targeting by $\mathrm{LHb}$ neuronal subtypes. tracing studies revealed that this subregion projects most heavily to the DRN, similar to 
340 retrograde tracers into the raphe nucleus (Quina et al., 2014). Interestingly, this region

341 also appears to receive dense input from serotonergic neurons of the raphe nuclei

342 (Huang et al., 2019), and express Htr2c as well as several other serotonin receptors

343 (See Table 4). We expect that this subregion also projects heavily to the lateral dorsal

344 tegmental nucleus (LDTg) and posterior hypothalamic area (PH), as retrograde

345 injections into these areas exclusively label the medial half of the LHb (Quina et al., 346 2014).

Summary

Progress in defining a function for the habenula has been hindered by incomplete understanding of its constituent cell-types and subregions. This study provides a

351 comprehensive description of the neuronal classes in the lateral and medial habenula

352 based on single-cell transcriptional profiling, FISH, and cell type specific monosynaptic

353 retrograde tracing (Figure S7). Future studies will improve our understanding of the

354 function of these habenula cell types by employing current optogenetic, chemogenetic,

355 and electrophysiological approaches for precise control and monitoring of individual

356 habenular populations. 


\section{MATERIALS AND METHODS}

\section{Mice}

373 The following mouse strains/lines were used in this study: C57BL/6J (The Jackson

374 Laboratory, Stock \# 000664), VGAT-IRES-Cre (The Jackson Laboratory, Stock \#

375 016962), DAT-IRES-Cre (The Jackson Laboratory, Stock \# 006660). Animals were kept

376 on a 12:12 regular light/dark cycle under standard housing conditions. All procedures

377 were performed in accordance with protocols approved by the Harvard Standing

378 Committee on Animal Care following guidelines described in the U.S. National Institutes

379 of Health Guide for the Care and Use of Laboratory Animals.

\section{Adeno-Associated Viruses (AAVs)}

382 Recombinant AAVs used for retrograde tracing experiments (AAV2/9-CAG-FLEX-TCB-

383 mCherry, AAV2/9-CAG-FLEX-RVG) were commercially obtained from the Boston

384 Children's Hospital Viral Core (Addgene \# 48332 and 48333, respectively). Virus

385 aliquots were stored at $-80^{\circ} \mathrm{C}$, and were injected at a concentration of approximately

$38610^{11}$ or $10^{12} \mathrm{GC} / \mathrm{ml}$, respectively.

\section{Rabies Viruses}

389 Rabies viruses used for retrograde tracing (B19G-SAD $\Delta$ G-EGFP) were generated in-

390 house (Wickersham et al., 2010). Virions were amplified from existing stocks in three

391 rounds of low-MOI passaging through BHK-B19G cells by transfer of filtered

392 supernatant, with 3 to 4 days between passages. Cells were grown at $35^{\circ} \mathrm{C}$ and $5 \%$

$393 \mathrm{CO}_{2}$ in DMEM with GlutaMAX (Thermo Scientific, \#10569010) supplemented with $5 \%$

394 heat-inactivated FBS (Thermo Scientific \#10082147) and antibiotic-antimycotic (Thermo

395 Scientific \#15240-062). Virions were concentrated from media from dishes containing

396 virion-generating cells by first collecting and incubating with benzonase nuclease

397 (1:1000, Millipore \#70664) at $37^{\circ} \mathrm{C}$ for $30 \mathrm{~min}$, followed by filtration through a $0.22 \mu \mathrm{m}$

398 PES filter. The filtered supernatant was transferred to ultracentrifuge tubes (Beckman

399 Coulter \#344058) with $2 \mathrm{ml}$ of $20 \%$ sucrose in dPBS cushion and ultracentrifugated at

40020,000 RPM (Beckman Coulter SW 32 Ti rotor) at $4^{\circ} \mathrm{C}$ for 2 hours. The supernatant was

401 discarded and the pellet was resuspended in APBS for 6 hours on an orbital shaker at 
$4024{ }^{\circ} \mathrm{C}$ before aliquots were prepared and frozen for long-term storage at $-80^{\circ} \mathrm{C}$.

403 Unpseudotyped rabies virus titers were estimated based on a serial dilution method

404 counting infected HEK 293T cells, and quantified as infectious units per $\mathrm{ml}(\mathrm{IU} / \mathrm{ml})$.

405 Pseudotyped rabies virus (SAD B19 strain, EnvA-RbV-GFP, Addgene\# 52487) was

406 commercially obtained from the Janelia Viral Tools Facility stored at $-80^{\circ} \mathrm{C}$, and injected

407 at a concentration of approximately $10^{8} \mathrm{IU} / \mathrm{ml}$.

\section{Stereotaxic Surgeries}

410 Adult mice were anesthetized with isoflurane (5\%) and placed in a small animal

411 stereotaxic frame (David Kopf Instruments). After exposing the skull under aseptic

412 conditions, viruses were injected through a pulled glass pipette at a rate of $50 \mathrm{nl} / \mathrm{min}$

413 using a UMP3 microsyringe pump (World Precision Instruments). Pipettes were slowly

414 withdrawn $(<100 \mu \mathrm{m} / \mathrm{s})$ at least $10 \mathrm{~min}$ after the end of the infusion. Following wound

415 closure, mice were placed in a cage with a heating pad until their activity was recovered

416 before returning to their home cage. Mice were given pre- and post-operative

417 subcutaneous ketoprofen ( $10 \mathrm{mg} / \mathrm{kg} / \mathrm{day})$ as an analgesic, and monitored daily for at

418 least 4 days post-surgery. Injection coordinates from Bregma for VTA were $-3.135 \mathrm{~mm}$

$419 \mathrm{~A} / \mathrm{P}, 0.4 \mathrm{~mm} \mathrm{M} / \mathrm{L}$, and $4.4 \mathrm{~mm} \mathrm{D} / \mathrm{V}$ and for $\mathrm{DRN}$ were $-6.077 \mathrm{~mm} \mathrm{~A} / \mathrm{P}, 0.1 \mathrm{~mm} \mathrm{M} / \mathrm{L}$, and -

$4203.33 \mathrm{~mm} \mathrm{D} / \mathrm{V}$ at $-40^{\circ}$. Injection volumes for specific anatomical regions and virus types

421 were as follows VTA: $200 \mathrm{~nL}$ AAV (mix of helper viruses), $250 \mathrm{~nL}$ EnvA-RbV-GFP (21

422 days after injection of AAV), DRN: $300 \mathrm{~nL}$ of RbV-GFP. Animals injected with rabies

423 virus were perfused 7 days after injection in a biosafety level 2 animal facility.

\section{Single Cell Dissociation and RNA Sequencing}

426 8- to 10-week old C57BL/6J mice were pair-housed in a regular 12:12 light/dark cycle

427 room prior to tissue collection. Mice were transcardially perfused with an ice-cold

428 choline cutting solution ( $110 \mathrm{mM}$ choline chloride, $25 \mathrm{mM}$ sodium bicarbonate, $12 \mathrm{mM}$

429 D-glucose, $11.6 \mathrm{mM}$ sodium L-ascorbate, $10 \mathrm{mM}$ HEPES, $7.5 \mathrm{mM}$ magnesium chloride,

$430 \quad 3.1 \mathrm{mM}$ sodium pyruvate, $2.5 \mathrm{mM}$ potassium chloride, $1.25 \mathrm{mM}$ sodium phosphate

431 monobasic, saturated with bubbling $95 \%$ oxygen/5\% carbon dioxide, $\mathrm{pH}$ adjusted to 7.4

432 using sodium hydroxide). Brains were rapidly dissected out and sliced into $200 \mu \mathrm{m}$ thick 
433 coronal sections on a vibratome (Leica Biosystems, VT1000) with a chilled cutting

434 chamber filled with choline cutting solution. Coronal slices containing the habenula were

435 then transferred to a chilled dissection dish containing a choline-based cutting solution

436 for microdissection. Dissected tissue chunks were transferred to cold HBSS-based

437 dissociation media (Thermo Fisher Scientific Cat. \# 14170112, supplemented to final

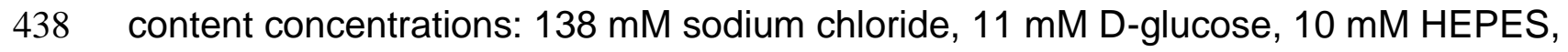

$4395.33 \mathrm{mM}$ potassium chloride, $4.17 \mathrm{mM}$ sodium bicarbonate, $2.12 \mathrm{mM}$ magnesium

440 chloride, $0.441 \mathrm{mM}$ potassium phosphate monobasic, $0.338 \mathrm{mM}$ sodium phosphate

441 monobasic, saturated with bubbling $95 \%$ oxygen $/ 5 \%$ carbon dioxide, $\mathrm{pH}$ adjusted to

4427.35 using sodium hydroxide) and kept on ice until dissections were completed.

443 Dissected tissue chunks for each sample were pooled for each hemisphere for the

444 subsequent dissociation steps. Tissue chunks were first mixed with a digestion cocktail

445 (dissociation media, supplemented to working concentrations: $20 \mathrm{U} / \mathrm{ml}$ papain, 0.05

$446 \mathrm{mg} / \mathrm{mL}$ DNAse I) and incubated at $34{ }^{\circ} \mathrm{C}$ for $90 \mathrm{~min}$ with gentle rocking. The digestion

447 was quenched by adding dissociation media supplemented with $0.2 \%$ BSA and 10

$448 \mathrm{mg} / \mathrm{ml}$ ovomucoid inhibitor (Worthington Cat. \# LK003128), and samples were kept

449 chilled for the rest of the dissociation procedure. Digested tissue was collected by brief

450 centrifugation (5 min, $300 \mathrm{~g}$ ), re-suspended in dissociation media supplemented with

$4510.2 \%$ BSA, $1 \mathrm{mg} / \mathrm{ml}$ ovomucoid inhibitor, and $0.05 \mathrm{mg} / \mathrm{mL}$ DNAse I. Tissue chunks were

452 then mechanically triturated using fine-tip plastic micropipette tips of progressively

453 decreasing size. The triturated cell suspension was filtered through a $40 \mu \mathrm{m}$ cell strainer

454 (Corning 352340) and washed in two repeated centrifugation (5 min, $300 \mathrm{~g}$ ) and re-

455 suspension steps to remove debris before a final re-suspension in dissociation media

456 containing $0.04 \%$ BSA and $15 \%$ OptiPrep (Sigma D1556). Cell density was calculated

457 based on hemocytometer counts and adjusted to approximately 100,000 cells $/ \mathrm{ml}$.

458 Single-cell encapsulation and RNA capture on the InDrop platform was performed at the

459 Harvard Medical School ICCB Single Cell Core using v3 chemistry hydrogels based on

460 previously described protocols (Zilionis et al., 2017). Suspensions were kept chilled until

461 the cells were flowed into the microfluidic device. Libraries were prepared and indexed

462 following the protocols referenced above, and sequencing-ready libraries were stored at 
$463-80^{\circ} \mathrm{C}$. Libraries from different samples were pooled and sequenced on an Illumina 464 NextSeq 500 (High Output v2 kits).

\section{Sequencing Data Processing}

467 NGS data was processed using previously a published pipeline in Python available at 468 [https://github.com/indrops/indrops] (Klein et al., 2015). Briefly, reads were filtered by 469 expected structure and sorted by the corresponding library index. Valid reads were then 470 demultiplexed and sorted by cell barcodes. Cell barcodes containing fewer than 250 471 total reads were discarded, and remaining reads were aligned to a reference mouse 472 transcriptome (Ensembl GRCm38 release 87) using Bowtie 1.1.1 ( $\mathrm{m}=200, \mathrm{n}=1, \mathrm{I}=$ $47315, e=1000$ ). Aligned reads were then quantified as UMI-filtered mapped read 474 (UMIFM) counts. UMIFM counts and quantification metrics for each cell were combined 475 into a single file sorted by library and exported as a gunzipped TSV file.

\section{Pre-Clustering Filtering and Normalization}

478 Analysis of the processed NGS data was performed in R (version 3.4.4) using the 479 Seurat package (version 2.3.4) (Butler et al., 2018; Satija et al., 2015). Cells with fewer 480 than 500 UMIFM counts and 200 genes were removed. The expression data matrix 481 (Genes $\times$ Cells) was filtered to retain genes with $>5$ UMIFM counts, and then loaded 482 into a Seurat object along with the library metadata for downstream processing. The 483 percentage of mitochondrial transcripts for each cell (percent.mito) was calculated and 484 added as metadata to the Seurat object. Cells in the object were further filtered using 485 the following parameters: $\mathrm{nUMI}$ - $\min$. 500, max. 18000; nGene - min. 200, max. 6000; 486 percent.mito - min. - Inf, max. 0.1. Low quality libraries identified as outliers on scatter 487 plots of quality control metrics (e.g. unusually low gradient on the nGene vs. nUMI) were 488 also removed from the dataset. Filtered Seurat objects were then log-normalized at 48910,000 transcripts per cell. Effects of latent variables (nUMI, percent.mito) were 490 estimated and regressed out using a GLM (ScaleData function, model. use =

491 "I inear"), and the scaled and centered residuals were used for dimensionality 492 reduction and clustering. 


\section{Cell Clustering and Cluster Identification}

495 Initial clustering was performed on the dataset using the first 20 PCs, and t-SNE was

496 used only for data visualization. Clustering was run using the SNN-based

497 FindClusters function using the SLM algorithm and 10 iterations. Clustering was

498 performed at varying resolution values, and we chose a final value of 1.2 for the

499 resolution parameter for this stage of clustering. Clusters were assigned preliminary

500 identities based on expression of combinations of known enriched genes for major cell

501 classes and types. The full list of enriched genes is provided in Table 2 and average

502 expression of all genes in all clusters is provided in Table 1. Low quality cells were

503 identified based on a combination of low gene/UMIFM counts and high levels of

504 mitochondrial and nuclear transcripts (e.g. Malat1, Meg3, Kcnq1ot1) typically clustered

505 together and were removed. Following assignment of preliminary identities, cells were

506 divided into data subsets as separate Seurat objects (LHb neurons and MHb neurons)

507 for further subclustering. The expression matrix for each data subset was further

508 filtered to include only genes expressed by the cells in the subset (minimum cell

509 threshold of $0.5 \%$ of cells in the subset). Subclustering was performed iteratively on

510 each data subset to resolve additional cell types and subtypes. Briefly, clustering was

511 run at high resolution, and the resulting clusters were ordered in a cluster dendrogram

512 using the BuildClusterTree function in Seurat which uses cluster averaged PCs for

513 calculating a PC distance matrix. Putative doublets/multiplets were identified based on

514 expression of known enriched genes for different cell types not in the cell subset (e.g.

515 neuronal and glial specific genes). Putative doublets tended to separate from other

516 cells and cluster together, and these clusters were removed from the dataset. Cluster

517 separation was evaluated using the AssessNodes function and inspection of

518 differentially expressed genes at each node. Clusters with poor separation, based

519 differential expression of mostly housekeeping genes, or activity dependent genes (see

520 Figure S2) were merged to avoid over-separation of the data. The dendrogram was

521 reconstructed after merging or removal of clusters, and the process of inspecting and

522 merging or removing clusters was repeated until all resulting clusters could be

523 distinguished based on a set of differentially expressed genes that we could validate

524 separately. To calculate the "ADG Score" (Figure S2) we used the AddModuleScore 
525 function in Seurat using a list of ADGs that were highly expressed in some of the $\mathrm{MHb}$

526 clusters (Fos, Fosb, Egr1, Junb, Nr4a1, Dusp18, Jun, Jund).

528 Differential Expression Tests

529 Tests for differential gene expression were performed using MAST (version 1.10.1)

530 (Finak et al., 2015) through the FindMarkersNode function in Seurat

531 (logfc.threshold $=0.25$, min.pct $=0.1)$. Adjusted $P$ values were corrected

532 using the Bonferroni correction for multiple comparisons $(P<0.05)$.

534 Fluorescence In-Situ Hybridization (FISH)

535 Mice were deeply anesthetized with isoflurane, decapitated, and their brains were

536 quickly removed and frozen in tissue freezing medium on dry ice. Brains were cut on a

537 cryostat (Leica CM 1950) into $30 \mu \mathrm{m}$ sections, adhered to SuperFrost Plus slides

538 (VWR), and immediately refrozen. Samples were fixed 4\% paraformaldehyde and

539 processed according to ACD RNAscope Fluorescent Multiplex Assay manual. Sections

540 were incubated at room temperature for 30 seconds with DAPI, excess liquid was

541 removed, and immediately coverslipped with ProLong antifade reagent (Molecular

542 Probes). Antisense probes for RbV-N, Gpr151, Sst, Chrm3, Vgf, Cre, Slc17a6,

543 Slc32a1, and Slc6a3 were purchased from Advanced Cell Diagonstics (ACD,

544 http://acdbio.com/). Sections were imaged at 1920 X 1440 pixels on a Keyence BZ-

545 X710 fluorescence microscope using a 10X, 0.45 NA air Nikon Plan Apo objective.

546 Individual imaging planes were overlaid and quantified for colocalization in Image

547 (NIH) and Matlab (Mathworks).

549 Image Analysis

550 FISH images were analyzed for "fluorescence coverage (\%)," meaning the proportion of

551 fluorescent pixels to total pixels in a cellular ROI, using a custom macro in Image $\mathrm{J}$ and

552 custom scripts in Matlab (Figure 4, S5, and S6). 5-10 images from at least 3 mice were

553 analyzed for each condition. Cell ROls were automatically determined based on

554 fluorescence signals in all three channels (or by fluorescence in the $R b V$ - $N$ channel for

555 rabies tracing experiments), and manually adjusted prior to analysis to ensure that all 
556 cell ROls reflected individual cells and not clusters. After background subtraction (the

557 signal outside of cell ROIs) and application of a fluorescence threshold (Renyi Entropy),

558 the amount of fluorescent pixels in each optical channel was counted within the cellular

559 ROI. All images compared underwent identical thresholding and no other manipulations

560 were made. These data were used to generate $X-Y$ plots displaying the percent

561 coverage for each channel per cell (Figure 4, S5, and S6).

\section{ACKNOWLEDGEMENTS}

564 The authors would like to thank Sarah Melzer and Adam Granger for assistance with

565 FISH analysis; James Levasseur for animal husbandry and genotyping; L. Worth for

566 administrative assistance; HMS ICCB Single Cell Core for assistance with scRNA-seq

567 experiments on the InDrop platform; The Bauer Core Facility at Harvard University for

568 sequencing support and the members of the Sabatini Lab for their helpful discussions

569 and advice. Starting materials for generating nonpseudotyped rabies virus is a

570 generous gift from B.K. Lim (UCSD). This work was supported by the Howard Hughes

571 Medical Institute (B.L.S.), NIH, National Institute of Neurological Disease and Stroke

572 (K99 NS105883 to M.L.W and NS103226 to B.L.S.).

\section{COMPETING INTERESTS}

575 The authors declare no financial or non-financial competing interests. 


\section{REFERENCES}

Andres, K.H., During, M. Von, Veh, R.W., 1999. Subnuclear organization of the rat habenular complexes. J. Comp. Neurol. 407, 130-150. https://doi.org/10.1002/(SICl)1096-9861(19990428)407:1<130::AIDCNE10>3.0.CO;2-8

Bakken, T.E., Hodge, R.D., Miller, J.A., Yao, Z., Nguyen, T.N., Aevermann, B., Barkan, E., Bertagnolli, D., Casper, T., Dee, N., Garren, E., Goldy, J., Graybuck, L.T., Kroll, M., Lasken, R.S., Lathia, K., Parry, S., Rimorin, C., Scheuermann, R.H., Schork, N.J., Shehata, S.I., Tieu, M., Phillips, J.W., Bernard, A., Smith, K.A., Zeng, H., Lein, E.S., Tasic, B., 2018. Single-nucleus and single-cell transcriptomes compared in matched cortical cell types. PLoS One 13, e0209648. https://doi.org/10.1371/journal.pone.0209648

Beier, K.T., Steinberg, E.E., DeLoach, K.E., Xie, S., Miyamichi, K., Schwarz, L., Gao, X.J., Kremer, E.J., Malenka, R.C., Luo, L., 2015. Circuit Architecture of VTA Dopamine Neurons Revealed by Systematic Input-Output Mapping. Cell 162, 622634. https://doi.org/10.1016/j.cell.2015.07.015

Broms, J., Antolin-Fontes, B., Tingström, A., Ibañez-Tallon, I., 2015. Conserved expression of the GPR151 receptor in habenular axonal projections of vertebrates. J. Comp. Neurol. 523, 359-380. https://doi.org/10.1002/cne.23664

Broms, J., Grahm, M., Haugegaard, L., Blom, T., Meletis, K., Tingström, A., 2017. Monosynaptic retrograde tracing of neurons expressing the G-protein coupled receptor Gpr151 in the mouse brain. J. Comp. Neurol. 525, 3227-3250. https://doi.org/10.1002/cne.24273

Butler, A., Hoffman, P., Smibert, P., Papalexi, E., Satija, R., 2018. Integrating single-cell transcriptomic data across different conditions, technologies, and species. Nat. Biotechnol. 36, 411-420. https://doi.org/10.1038/nbt.4096

Cohen, J.Y., Haesler, S., Vong, L., Lowell, B.B., Uchida, N., 2012. Neuron-type-specific signals for reward and punishment in the ventral tegmental area. Nature 482, 8588. https://doi.org/10.1038/nature10754

Concha, M.L., Wilson, S.W., 2001. Asymmetry in the epithalamus of vertebrates. J. Anat. 199, 63-84. https://doi.org/10.1046/j.1469-7580.2001.19910063.x 
618

619

620

621

622

623

624

625

626

627

628

629

630

631

632

633

634

635

636

637

638

639

640

641

642

643

644

645

646

647

648

D'Souza, M.S., 2016. Neuroscience of nicotine for addiction medicine: novel targets for smoking cessation medications. Prog. Brain Res. 223, 191-214. https://doi.org/10.1016/bs.pbr.2015.07.008

Finak, G., McDavid, A., Yajima, M., Deng, J., Gersuk, V., Shalek, A.K., Slichter, C.K., Miller, H.W., McElrath, M.J., Prlic, M., Linsley, P.S., Gottardo, R., 2015. MAST: a flexible statistical framework for assessing transcriptional changes and characterizing heterogeneity in single-cell RNA sequencing data. Genome Biol. 16, 278. https://doi.org/10.1186/s13059-015-0844-5

Fowler, C.D., Lu, Q., Johnson, P.M., Marks, M.J., Kenny, P.J., 2011. Habenular a5 nicotinic receptor subunit signalling controls nicotine intake. Nature 471, 597-601. https://doi.org/10.1038/nature09797

Gonçalves, L., Sego, C., Metzger, M., 2012. Differential projections from the lateral habenula to the rostromedial tegmental nucleus and ventral tegmental area in the rat. J. Comp. Neurol. 520, 1278-300. https://doi.org/10.1002/cne.22787

Herkenham, M., Nauta, W.J., 1977. Afferent connections of the habenular nuclei in the rat. A horseradish peroxidase study, with a note on the fiber-of-passage problem. J. Comp. Neurol. 173, 123-46. https://doi.org/10.1002/cne.901730107

Herkenham, M., Nauta, W.J.H., 1979. Efferent connections of the habenular nuclei in the rat. J. Comp. Neurol. 187, 19-47. https://doi.org/10.1002/cne.901870103

Hikosaka, O., 2010. The habenula: from stress evasion to value-based decisionmaking. Nat. Rev. Neurosci. 11, 503-13. https://doi.org/10.1038/nrn2866

Hsu, Y.-W.A., Morton, G., Guy, E.G., Wang, S.D., Turner, E.E., 2016. Dorsal Medial Habenula Regulation of Mood-Related Behaviors and Primary Reinforcement by Tachykinin-Expressing Habenula Neurons. eNeuro 3. https://doi.org/10.1523/ENEURO.0109-16.2016

Hsu, Y.-W.A., Wang, S.D., Wang, S., Morton, G., Zariwala, H.A., de la Iglesia, H.O., Turner, E.E., 2014. Role of the Dorsal Medial Habenula in the Regulation of Voluntary Activity, Motor Function, Hedonic State, and Primary Reinforcement. J. Neurosci. 34, 11366-11384. https://doi.org/10.1523/JNEUROSCI.1861-14.2014 Huang, K.W., Ochandarena, N.E., Philson, A.C., Hyun, M., Birnbaum, J.E., Cicconet, M., Sabatini, B.L., 2019. Molecular and anatomical organization of the dorsal raphe 
nucleus. Elife 8. https://doi.org/10.7554/eLife.46464

Ji, H., Shepard, P.D., 2007. Lateral habenula stimulation inhibits rat midbrain dopamine neurons through a $\mathrm{GABA}(\mathrm{A})$ receptor-mediated mechanism. J. Neurosci. 27, 692330. https://doi.org/10.1523/JNEUROSCI.0958-07.2007

Klein, A.M., Mazutis, L., Akartuna, I., Tallapragada, N., Veres, A., Li, V., Peshkin, L., Weitz, D.A., Kirschner, M.W., 2015. Droplet barcoding for single-cell transcriptomics applied to embryonic stem cells. Cell 161, 1187-1201. https://doi.org/10.1016/j.cell.2015.04.044

Lammel, S., Lim, B.K., Ran, C., Huang, K.W., Betley, M.J., Tye, K.M., Deisseroth, K., Malenka, R.C., 2012. Input-specific control of reward and aversion in the ventral tegmental area. Nature 491, 212-7. https://doi.org/10.1038/nature11527

Lecca, S., Meye, F.J., Mameli, M., 2014. The lateral habenula in addiction and depression: an anatomical, synaptic and behavioral overview. Eur. J. Neurosci. 39, 1170-1178. https://doi.org/10.1111/ejn.12480

Lein, E.S., Hawrylycz, M.J., Ao, N., Ayres, M., Bensinger, A., Bernard, A., Boe, A.F., Boguski, M.S., Brockway, K.S., Byrnes, E.J., Chen, Lin, Chen, Li, Chen, T.-M., Chi Chin, M., Chong, J., Crook, B.E., Czaplinska, A., Dang, C.N., Datta, S., Dee, N.R., Desaki, A.L., Desta, T., Diep, E., Dolbeare, T.A., Donelan, M.J., Dong, H.-W., Dougherty, J.G., Duncan, B.J., Ebbert, A.J., Eichele, G., Estin, L.K., Faber, C., Facer, B.A., Fields, R., Fischer, S.R., Fliss, T.P., Frensley, C., Gates, S.N., Glattfelder, K.J., Halverson, K.R., Hart, M.R., Hohmann, J.G., Howell, M.P., Jeung, D.P., Johnson, R.A., Karr, P.T., Kawal, R., Kidney, J.M., Knapik, R.H., Kuan, C.L., Lake, J.H., Laramee, A.R., Larsen, K.D., Lau, C., Lemon, T.A., Liang, A.J., Liu, Y., Luong, L.T., Michaels, J., Morgan, J.J., Morgan, R.J., Mortrud, M.T., Mosqueda, N.F., Ng, L.L., Ng, R., Orta, G.J., Overly, C.C., Pak, T.H., Parry, S.E., Pathak, S.D., Pearson, O.C., Puchalski, R.B., Riley, Z.L., Rockett, H.R., Rowland, S.A., Royall, J.J., Ruiz, M.J., Sarno, N.R., Schaffnit, K., Shapovalova, N. V., Sivisay, T., Slaughterbeck, C.R., Smith, S.C., Smith, K.A., Smith, B.I., Sodt, A.J., Stewart, N.N., Stumpf, K.-R., Sunkin, S.M., Sutram, M., Tam, A., Teemer, C.D., Thaller, C., Thompson, C.L., Varnam, L.R., Visel, A., Whitlock, R.M., Wohnoutka, P.E., Wolkey, C.K., Wong, V.Y., Wood, M., Yaylaoglu, M.B., Young, R.C., Youngstrom, B.L., 
680

681

682

683

684

685

686

687

688

689

690

691

692

693

694

695

696

697

698

699

700

701

702

703

704

705

706

707

708

709

710

Feng Yuan, X., Zhang, B., Zwingman, T.A., Jones, A.R., 2007. Genome-wide atlas of gene expression in the adult mouse brain. Nature 445, 168-176. https://doi.org/10.1038/nature05453

Li, B., Piriz, J., Mirrione, M., Chung, C., Proulx, C.D., Schulz, D., Henn, F., Malinow, R., 2011. Synaptic potentiation onto habenula neurons in the learned helplessness model of depression. Nature 470, 535-539. https://doi.org/10.1038/nature09742

Li, K., Zhou, T., Liao, L., Yang, Z., Wong, C., Henn, F., Malinow, R., Yates, J.R., Hu, H., 2013. $\beta$ CaMKII in lateral habenula mediates core symptoms of depression. Science 341, 1016-20. https://doi.org/10.1126/science.1240729

Maroteaux, M., Mameli, M., 2012. Cocaine Evokes Projection-Specific Synaptic Plasticity of Lateral Habenula Neurons. J. Neurosci. 32, 12641-12646. https://doi.org/10.1523/JNEUROSCI.2405-12.2012

Matsumoto, M., Hikosaka, O., 2007. Lateral habenula as a source of negative reward signals in dopamine neurons. Nature 447, 1111-5. https://doi.org/10.1038/nature05860

Meye, F.J., Soiza-Reilly, M., Smit, T., Diana, M.A., Schwarz, M.K., Mameli, M., 2016. Shifted pallidal co-release of GABA and glutamate in habenula drives cocaine withdrawal and relapse. Nat. Neurosci. 19, 1019-1024. https://doi.org/10.1038/nn.4334

Mizumori, S.J.Y., Baker, P.M., 2017. The Lateral Habenula and Adaptive Behaviors. Trends Neurosci. 40, 481-493. https://doi.org/10.1016/j.tins.2017.06.001 Moffitt, J.R., Bambah-Mukku, D., Eichhorn, S.W., Vaughn, E., Shekhar, K., Perez, J.D., Rubinstein, N.D., Hao, J., Regev, A., Dulac, C., Zhuang, X., 2018. Molecular, spatial, and functional single-cell profiling of the hypothalamic preoptic region. Science 362, eaau5324. https://doi.org/10.1126/science.aau5324

Morales, M., Margolis, E.B., 2017. Ventral tegmental area: cellular heterogeneity, connectivity and behaviour. Nat. Rev. Neurosci. 18, 73-85. https://doi.org/10.1038/nrn.2016.165

Pandey, S., Shekhar, K., Regev, A., Schier, A.F., 2018. Comprehensive Identification and Spatial Mapping of Habenular Neuronal Types Using Single-Cell RNA-Seq. Curr. Biol. 28, 1052-1065.e7. https://doi.org/10.1016/j.cub.2018.02.040 
711 Petzel, A., Bernard, R., Poller, W.C., Veh, udiger W., 2017. Anterior and posterior parts of the rat ventral tegmental area and the rostromedial tegmental nucleus receive topographically distinct afferents from the lateral habenular complex Comparative Neurology. J Comp Neurol 525, 2310-2327. https://doi.org/10.1002/cne.24200

Proulx, C.D., Hikosaka, O., Malinow, R., 2014. Reward processing by the lateral habenula in normal and depressive behaviors. Nat. Neurosci. 17, 1146-1152. https://doi.org/10.1038/nn.3779

Quina, L. a., Tempest, L., Ng, L., Harris, J., Ferguson, S., Jhou, T., Turner, E.E., 2014. Efferent pathways of the mouse lateral habenula. J. Comp. Neurol. 00. https://doi.org/10.1002/cne.

Quina, L.A., Tempest, L., Ng, L., Harris, J.A., Ferguson, S., Jhou, T.C., Turner, E.E., 2015. Efferent Pathways of the Mouse Lateral Habenula. J. Comp. Neurol. 523, 32-60. https://doi.org/10.1002/cne.23662

Ren, J., Qin, C., Hu, F., Tan, J., Qiu, L., Zhao, S., Feng, G., Luo, M., 2011. Habenula "Cholinergic" Neurons Corelease Glutamate and Acetylcholine and Activate Postsynaptic Neurons via Distinct Transmission Modes. Neuron 69, 445-452. https://doi.org/10.1016/J.NEURON.2010.12.038

Root, D.H., Mejias-aponte, C. a, Zhang, S., Wang, H., Hoffman, A.F., Lupica, C.R., Morales, M., 2014. Single rodent mesohabenular axons release glutamate and GABA. Nat. Neurosci. 17. https://doi.org/10.1038/nn.3823 reconstruction of single-cell gene expression data. Nat. Biotechnol. 33, 495-502. https://doi.org/10.1038/nbt.3192

Saunders, A., Macosko, E.Z., Wysoker, A., Goldman, M., Krienen, F.M., de Rivera, H., R.M., 2014. Differential expression and function of nicotinic acetylcholine receptors in subdivisions of medial habenula. J. Neurosci. 34, 9789-802. 
https://doi.org/10.1523/JNEUROSCI.0476-14.2014

Soria-Gómez, E., Busquets-Garcia, A., Hu, F., Mehidi, A., Cannich, A., Roux, L., Louit, I., Alonso, L., Wiesner, T., Georges, F., Verrier, D., Vincent, P., Ferreira, G., Luo, M., Marsicano, G., 2015. Habenular CB1 Receptors Control the Expression of Aversive Memories. Neuron 88, 306-13. https://doi.org/10.1016/j.neuron.2015.08.035

Tasic, B., Yao, Z., Graybuck, L.T., Smith, K.A., Nguyen, T.N., Bertagnolli, D., Goldy, J., Garren, E., Economo, M.N., Viswanathan, S., Penn, O., Bakken, T., Menon, V., Miller, J., Fong, O., Hirokawa, K.E., Lathia, K., Rimorin, C., Tieu, M., Larsen, R., Casper, T., Barkan, E., Kroll, M., Parry, S., Shapovalova, N. V., Hirschstein, D., Pendergraft, J., Sullivan, H.A., Kim, T.K., Szafer, A., Dee, N., Groblewski, P., Wickersham, I., Cetin, A., Harris, J.A., Levi, B.P., Sunkin, S.M., Madisen, L., Daigle, T.L., Looger, L., Bernard, A., Phillips, J., Lein, E., Hawrylycz, M., Svoboda, K., Jones, A.R., Koch, C., Zeng, H., 2018. Shared and distinct transcriptomic cell types across neocortical areas. Nature 563, 72-78. https://doi.org/10.1038/s41586-0180654-5

Tian, J., Uchida, N., 2015. Habenula Lesions Reveal that Multiple Mechanisms Underlie Dopamine Prediction Errors. Neuron 87, 1304-1316. https://doi.org/10.1016/j.neuron.2015.08.028

Tritsch, N.X., Ding, J.B., Sabatini, B.L., 2012. Dopaminergic neurons inhibit striatal output through non-canonical release of GABA. Nature 490, 262-6. https://doi.org/10.1038/nature11466

Wagner, F., French, L., Veh, R.W., 2016. Transcriptomic-anatomic analysis of the mouse habenula uncovers a high molecular heterogeneity among neurons in the lateral complex, while gene expression in the medial complex largely obeys

772 Wallace, M.L., Saunders, A., Huang, K.W., Philson, A.C., Goldman, M., Macosko, E.Z., 

McCarroll, S.A., Sabatini, B.L., 2017. Genetically Distinct Parallel Pathways in the Entopeduncular Nucleus for Limbic and Sensorimotor Output of the Basal Ganglia. Neuron 94, 138-152.e5. https://doi.org/10.1016/j.neuron.2017.03.017

Wang, D., Li, Y., Feng, Q., Guo, Q., Zhou, J., Luo, M., 2017. Learning shapes the aversion and reward responses of lateral habenula neurons. Elife 6. https://doi.org/10.7554/eLife.23045

Watabe-Uchida, M., Zhu, L., Ogawa, S.K., Vamanrao, A., Uchida, N., 2012. Wholebrain mapping of direct inputs to midbrain dopamine neurons. Neuron 74, 858-73. https://doi.org/10.1016/j.neuron.2012.03.017

Wickersham, I.R., Lyon, D.C., Barnard, R.J.O., Mori, T., Finke, S., Conzelmann, K.-K., Young, J.A.T., Callaway, E.M., 2007. Monosynaptic restriction of transsynaptic tracing from single, genetically targeted neurons. Neuron 53, 639-47. https://doi.org/10.1016/j.neuron.2007.01.033

Wickersham, I.R., Sullivan, H.A., Seung, H.S., 2010. Production of glycoprotein-deleted rabies viruses for monosynaptic tracing and high-level gene expression in neurons. Nat. Protoc. 5, 595-606. https://doi.org/10.1038/nprot.2009.248

Yetnikoff, L., Cheng, A.Y., Lavezzi, H.N., Parsley, K.P., Zahm, D.S., 2015. Sources of input to the rostromedial tegmental nucleus, ventral tegmental area, and lateral habenula compared: A study in rat. J. Comp. Neurol. 523, 2426-56. https://doi.org/10.1002/cne.23797

Zahm, D.S., Root, D.H., 2017. Review of the cytology and connections of the lateral habenula, an avatar of adaptive behaving. Pharmacol. Biochem. Behav. 162, 3-21. https://doi.org/10.1016/j.pbb.2017.06.004

Zeisel, A., Hochgerner, H., Lönnerberg, P., Johnsson, A., Memic, F., van der Zwan, J., Häring, M., Braun, E., Borm, L.E., La Manno, G., Codeluppi, S., Furlan, A., Lee, K., Skene, N., Harris, K.D., Hjerling-Leffler, J., Arenas, E., Ernfors, P., Marklund, U., Linnarsson, S., 2018. Molecular Architecture of the Mouse Nervous System. Cell 174, 999-1014.e22. https://doi.org/10.1016/j.cell.2018.06.021

Zhang, L., Hernández, V.S., Swinny, J.D., Verma, A.K., Giesecke, T., Emery, A.C., Mutig, K., Garcia-Segura, L.M., Eiden, L.E., 2018. A GABAergic cell type in the lateral habenula links hypothalamic homeostatic and midbrain motivation circuits 
with sex steroid signaling. Transl. Psychiatry 8, 50. https://doi.org/10.1038/s41398018-0099-5

Zhao-Shea, R., Liu, L., Pang, X., Gardner, P.D., Tapper, A.R., 2013. Activation of GABAergic Neurons in the Interpeduncular Nucleus Triggers Physical Nicotine Withdrawal Symptoms. Curr. Biol. 23, 2327-2335. https://doi.org/10.1016/j.cub.2013.09.041

Zhao, H., Zhang, B.-L., Yang, S.-J., Rusak, B., 2015. The role of lateral habenuladorsal raphe nucleus circuits in higher brain functions and psychiatric illness. Behav. Brain Res. 277, 89-98. https://doi.org/10.1016/j.bbr.2014.09.016 Functional Long-Range Circuits Controlling the Activity of Serotonergic Neurons in the Dorsal Raphe Nucleus. Cell Rep. 18, 3018-3032. https://doi.org/10.1016/j.celrep.2017.02.077

Zilionis, R., Nainys, J., Veres, A., Savova, V., Zemmour, D., Klein, A.M., Mazutis, L., 2017. Single-cell barcoding and sequencing using droplet microfluidics. Nat. Protoc. 12, 44-73. https://doi.org/10.1038/nprot.2016.154 


\section{FIGURE LEGENDS}

836 Figure 1: High-throughput single cell transcriptomic profiling of the habenula.

837 (A) Schematic for scRNA-seq using the inDrop platform. Tissue containing the habenula

838 was microdissected from acute coronal brain slices prepared from adult mice (1). Tissue

839 chunks were digested in a cocktail of proteases and followed by trituration and filtration

840 to obtain a cell suspension (2). Single cells were encapsulated using a droplet-based

841 microfluidic device (3) for cell barcoding and mRNA capture (4). RNA sequencing (5)

842 and bioinformatics analysis followed (6). (B) t-SNE plot of the processed dataset

843 containing 7,506 cells from 6 animals. Cells are color-coded according to the cluster

844 labels shown in (C). (C) Left: Dendrogram with cell class labels corresponding to

845 clusters shown in (B). Right: Dot plot displaying expression of example enriched genes

846 used to identify each major cell class. The color of each dot (blue to red) indicates the

847 relative log-scaled expression of each gene whereas the dot size indicates the fraction

848 of cells expressing the gene.

849 Figure 2: MHb neuron subtypes can be distinguished transcriptionally.

850 (A) Location of $\mathrm{MHb}$ and ISH of Tac2 expression from the Allen Institute Database.

851 Tac2 expression is restricted to cells in the $\mathrm{MHb}$ in this region. (B) Tac2 serves as an

852 excellent marker for MHb neurons in the dataset of SCTs (Scale on right shows

853 normalized (log) gene expression.) (C) Sample ISH images from the Allen Institute

854 Database showing selected differentially expressed genes for distinct transcriptionally

855 defined neuronal subtypes in MHb. (D) Left: Dendrogram with MHb subtype labels

856 corresponding to clusters shown in (Figure S2C). Right: Heatmap showing the relative

857 expression (mean z- scored) of selected genes that are enriched in each $\mathrm{MHb}$ neuron

858 subtype. Spatial distributions of enriched genes highlighted in (C) are labeled in red. 
Figure 3: Characterization of genes differentially expressed between LHb neuron

860 subtypes.

861 (A) Location of LHb clusters and ISH Gap43 expression from the Allen Institute

862 Database. Gap43 is highly expressed in neurons of the LHb and surrounding thalamus

863 in this region, but excluded from MHb neurons. (B) Gap43 serves as an excellent

864 marker for $\mathrm{LHb}$ neurons in the dataset of single cell transcriptomes (Scale on right

865 shows normalized (log) gene expression.) $(\mathbf{C})$ Left: Illustration showing patterns of gene

866 expression observed for genes shown for sample ISH to the right. Right: Sample ISH

867 images from the Allen Institute Database showing selected differentially expressed

868 genes for distinct transcriptionally defined neuronal subtypes in LHb. (D) Left:

869 Dendrogram with LHb neuron labels corresponding spatial locations of differentially

870 expressed genes within the LHb. Right: Heatmap showing the relative expression of

871 selected genes that are enriched in each LHb neuron subtype. Spatial distributions of

872 enriched genes highlighted in (C) are labeled in red.

873 Figure 4: FISH confirms that differentially expressed genes from LHb subclusters

874 are nonoverlapping and confined to specific spatial locations of LHb.

875 (A) Left: Sample FISH of two differentially expressed LHb genes ( Vgf (yellow) and

876 Chrm3 (magenta)), with distinct spatial profiles (LHb outlined with gray dashed line).

877 Right: Quantification of fluorescence coverage of single cells for FISH of Vgf and Chrm3

878 in LHb neurons ( $n=444$ cells, 3 mice). (B) Left: Sample FISH of two differentially

879 expressed LHb genes (Sst (yellow) and Chrm3 (magenta)), with distinct spatial profiles.

880 Right: Quantification of fluorescence coverage of single cells for FISH of Sst and Chrm3

881 in LHb neurons ( $n=252$ cells, 3 mice). (C) Sample FISH of two differentially expressed 
882 LHb genes (Gpr151 (yellow) and Chrm3 (magenta)), with distinct spatial profiles

883 (illustrated in upper right inset), LHb outlined in gray dashed line. (F) Quantification of

884 fluorescence coverage of single cells for FISH of Gpr151 and Chrm3 in LHb neurons

885 ( $n=240$ cells, 3 mice). (D) Left: Sample FISH of two differentially expressed LHb genes

886 (Sst (yellow) and Gpr151 (magenta)), with distinct spatial profiles. Right: Quantification

887 of fluorescence coverage of single cells for FISH of Sst and Gpr151 in LHb neurons ( $\mathrm{n}=$

888112 cells, 3 mice).

889 Figure 5: Distinct LHb neuron subtypes prefer different downstream targets, but

890 all subtypes target both VTA and DRN.

891 (A) Location of sites for AAV helper viruses (AAV-FLEX-TVA-mCh and AAV-FLEX-

892 RVG) and pseudotyped rabies virus (EnvA-RbV-GFP) injection into VTA. (B) Location

893 of non-pseudotyped rabies virus (RbV-GFP) injection into DRN. (C) Sample habenula

894 FISH images for $R b V-N$ and $C h r m 3$ following viral injection into either VTA or DRN. (D)

895 Quantification of the proportion of $R b V-N$ labeled neurons that overlapped with the

896 enriched genes for distinct LHb neuron subtypes (VGAT-IRES-Cre $n=1430$ cells/ 4

897 mice, DAT-IRES-Cre $n=549 / 3$ mice, $D R N n=465 / 3$ mice). Filled rectangles are the

898 mean and error bars are \pm SEM, see Table 6 for statistical comparisons. 
SUPPLEMENTARY INFORMATION

906 Figure S1 (related to Figure 1): Comparison of cell type composition across

907 hemispheres and gene diversity, mitochondrial genes, and UMls across cell

908 types.

909 (A) t-SNE plot of the dataset with cells color-coded by the hemisphere from which the

910 sample was acquired. (B) Bar plots showing the percentage of cells in each

911 hemisphere that are categorized into each of the 12 major cell types. (C) Violin plots of

912 the number of genes (top), unique molecular identifiers (UMIs, middle), and percentage

913 of mitochondrial genes (bottom) for each of the 12 cell types. Each point represents a

914 single cell and filled area is a probability distribution of all the cells in that category.

915

916 Figure S2 (related to Figure 2): Subclustering of MHb neurons before and after

917 subtraction of heterogeneity introduced by elevated expression of activity

918 dependent genes (ADGs).

919 (A) t-SNE plot of subclustered MHb neurons extracted from cells in Figure 1B. (B) t-

920 SNE plot showing three clusters of cells (top) that expressed elevated levels of several

921 ADGs (Fos, Fosb, Egr1, Junb, Dusp18, etc.). (C) t-SNE plot after regressing out the

922 principle component (PC) that included many of the ADGs shown in (B). Cells from

923 clusters that were high in ADG expression were now intermingled with clusters that we

924 defined by the spatial location of their DEGs (See also Figure 2C and D). (D) t-SNE plot

925 showing ADG score following regressing out of the PC containing ADGs. (E) All 12

926 statistically significant PCs for the MHb neuron clusters shown above. PC number 4 
927 (red) contained several ADGs. (F) The top 25 genes associated with PC4 (the ADG

928 PC) contained several known ADGs highlighted in red.

930 Figure S3 (related to Figure 2): Sample ISH images showing spatial distribution of

931 selected differentially expressed genes in MHb. (A-J) Sample ISH images from the

932 Allen Institute Database showing selected differentially expressed genes for distinct

933 transcriptionally defined neuronal subtypes in $\mathrm{MHb}$. Gene name is in the upper right of

934 each image and subregion where gene is enriched is on the left. Scale bar $=250 \mu \mathrm{m}$.

935

936 Figure S4 (related to Figure 2 and 3): Differentially expressed genes define

937 distinct habenular subtypes.

938 (A) Left: Dendrogram for subclustering of all neurons shown in Figure 2 and 3. Right:

939 Dot plot displaying expression of example differentially expressed genes used to identify

940 each subtype of habenula neuron. The color of each dot (blue to red) indicates the

941 relative expression of each gene whereas the dot size indicates the fraction of cells

942 expressing the gene. Only representative genes are shown for entire list of DEGs see

943 Table 3 and 5.

944

945 Figure S5 (related to Figure 5): Cells from all 4 LHb subtypes project to both the

946 VTA and DRN.

947 (A) Quantification of fluorescence coverage of single cells for FISH of selected enriched

948 genes in LHb neurons that were positive for $R b V-N$ following monosynaptic retrograde

949 tracing from VGAT-IRES-Cre+ neurons in the VTA (left: $n=521$ cells, 4 mice; center: $n=$ 
950742 cells, 4 mice; right: $n=167$ cells, 2 mice). (B) Quantification of fluorescence

951 coverage of single cells for FISH of selected enriched genes in LHb neurons that were

952 positive for $R b V-N$ following monosynaptic retrograde tracing from DAT-IRES-Cre+

953 neurons in the VTA (left: $n=233$ cells, 3 mice; center: $n=233$ cells, 3 mice; right: $n=103$

954 cells, 3 mice). (C) Quantification of fluorescence coverage of single cells for FISH of

955 selected enriched genes in LHb neurons that were positive for $R b V-N$ following injection

956 of RbV-GFP into the DRN (left: $n=163$ cells, 3 mice; center: $n=133$ cells, 3 mice; right:

$957 \mathrm{n}=169$ cells, 3 mice).

958

959 Figure S6 (related to Figure 5): Quantification and genetic characterization of VTA

960 starter cells from monosynaptic retrograde tracing.

961 (A) Left: Coronal section of injection site into VTA and starter cells location for Cre-

962 dependent monosynaptic retrograde tracing experiments. Right: FISH for $R b V-N$ to

963 demonstrate the location of rabies infected cells in the VTA. (B) Left: Coronal section of

964 injection site into DRN Cre-independent retrograde tracing experiments. Right: FISH for

$965 R b V-N$ to demonstrate the location of rabies infected cells in the DRN. (C) Left:

966 Quantification of fluorescence coverage of single putative starter cells (Cre+ and RbV-

$967 \mathrm{~N}+)$ for FISH of Cre and SIc17a6 in VTA neurons of the VGAT-IRES-Cre animals $(\mathrm{n}=$

968567 cells, 4 mice). Right: The proportion of putative starter cells that expressed

969 Slc17a6. There is a subset of VGAT-IRES-Cre+ neurons in the VTA that co-express

970 Slc17a6 (Root et al., 2014). (D) Left: Quantification of fluorescence coverage of single

971 putative starter cells (SIc6a3+ and RbV-N+) for FISH of Slc6a3 and Slc32a1 in VTA

972 neurons of the DAT-IRES-Cre animals ( $n=566$ cells, 3 mice). Right: The proportion of 
973 putative starter cells that expressed Slc32a1. (E) Negative control for EnvA

974 pseudotyping of the rabies virus (EnvA-RbV-GFP) showing a coronal section following

975 injection of EnvA-RbV-GFP into the VTA without prior infection by AAV-TVA-mCh.

976 Without co injecting AAV-TVA-mCh, EnvA-RbV-GFP cannot infect neurons, thus no

977 GFP expression. Filled rectangles represent the mean and error bars are \pm SEM.

978 Figure S7 (related to Figure 2, 3, and 4): A map of habenula subregions based on

979 single cell transcriptomic profiling.

980 (A) Habenular subregions are outlined in black, MHb subregions are green and LHb

981 subregions are magenta. The location of borders is a rough estimate of a boundary

982 between transcriptionally defined neuronal subtypes and previous literature. 
Figure 1 bioRxiv preprint doi: https://doi.org/10.1101/743401; this version posted August 21, 2019. The copyright holder for this prepri certified by peer review) is the author/funder, who has granted bioRxiv a license to display the preprint in perpetuity. It is mad A InDrop Workflow aCC-BYBNC-ND 4.0 International liferençophages

1) Habenula dissection

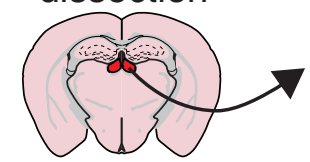

2) Cell isolation

3) Cell suspension

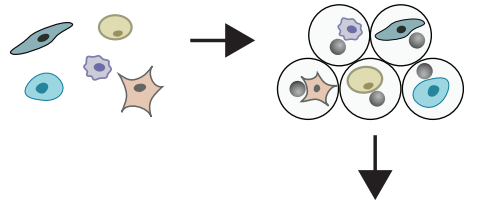

6) Clustering and 5) RNA-seq Analysis

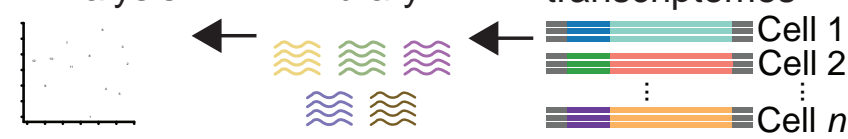

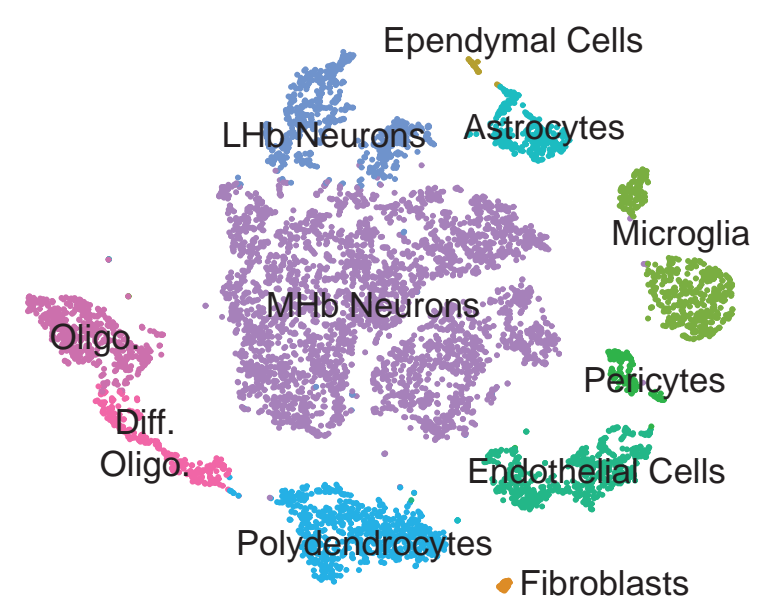

C

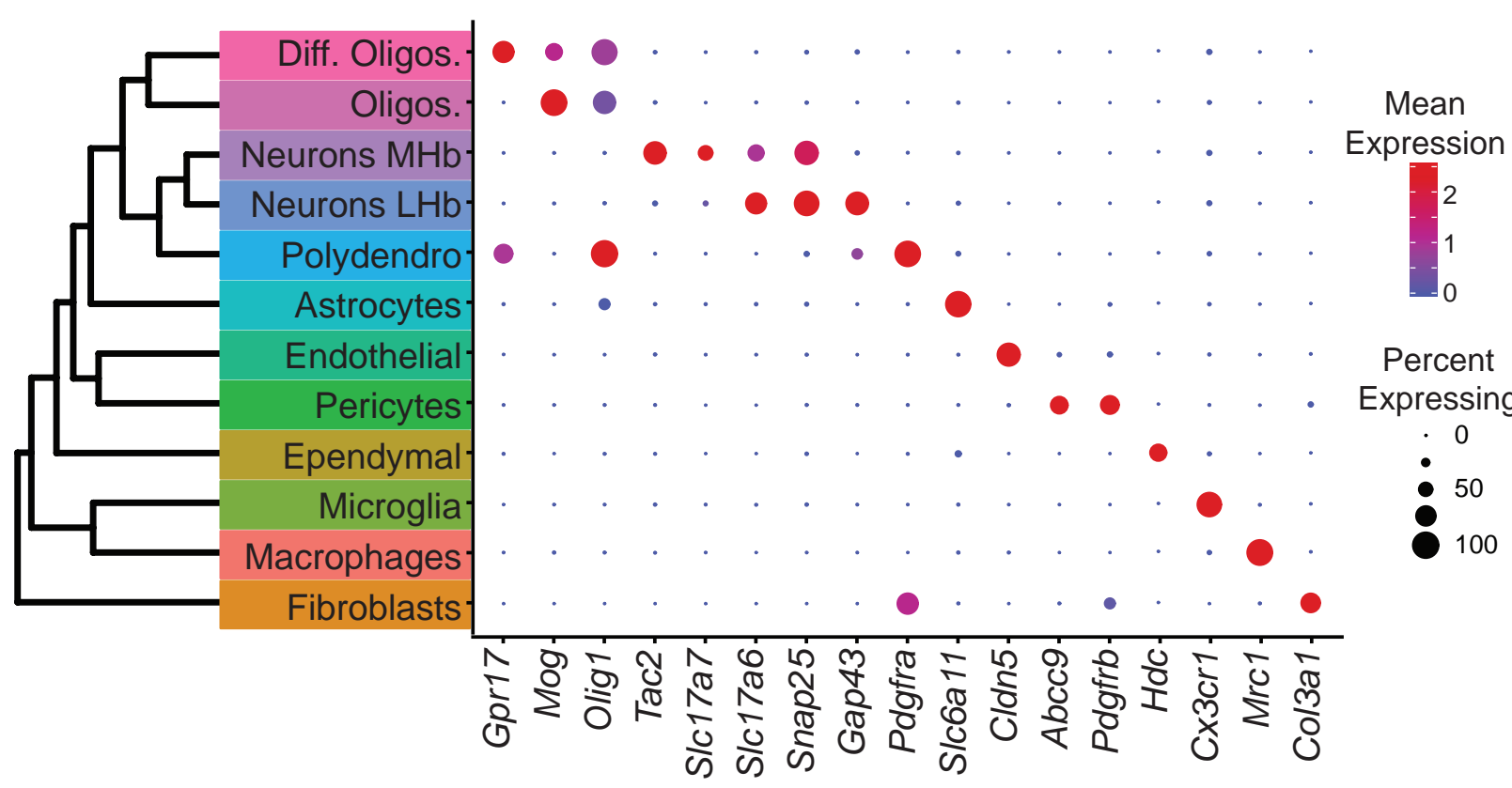


Figure 2 bioRxiv preprint doi: https://doi.org/10.1101/743401; this version posted August 21, 2019. The copyright holder for this prepri certified by peer review) is the author/funder, who has granted bioRxiv a license to display the preprint in perpetuity. It is mad A aQB-BY-NC-ND 4.0 International license.

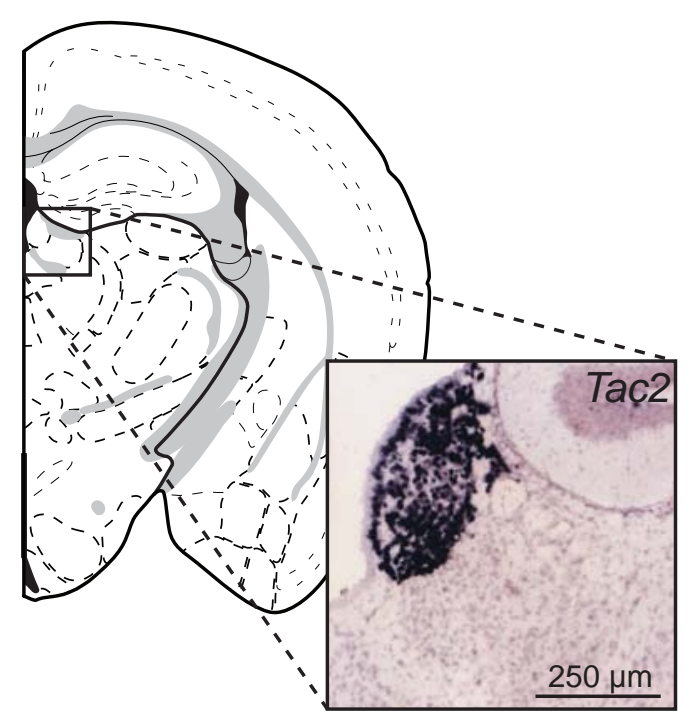

Tac2

C
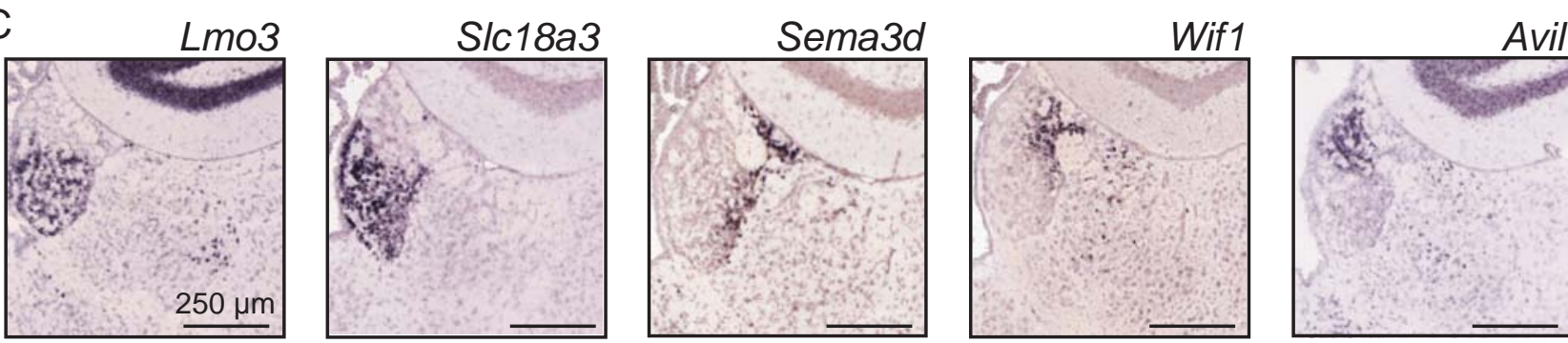

D
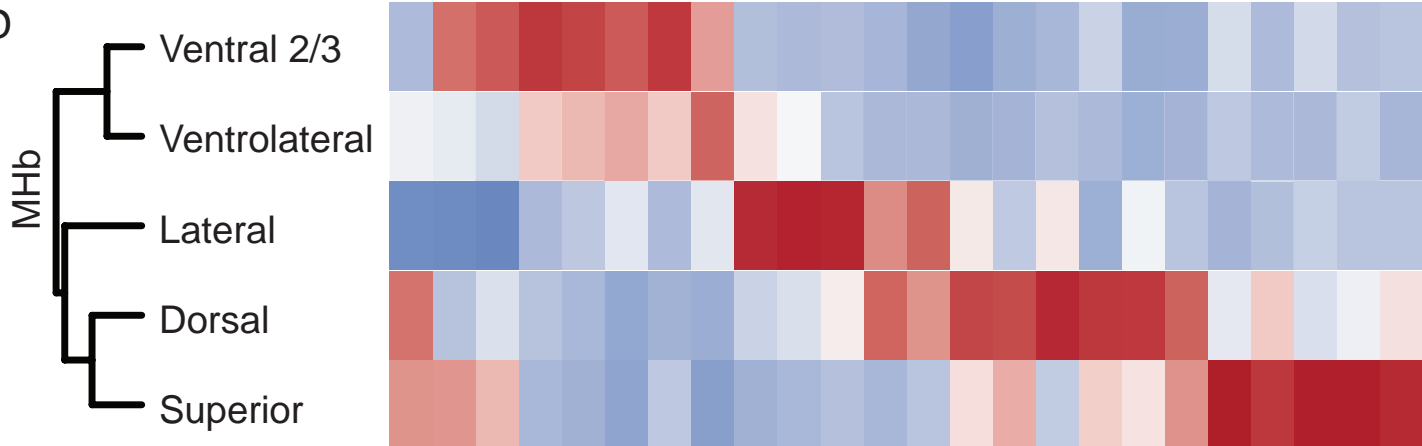

Mean

Z-Scored

Expression

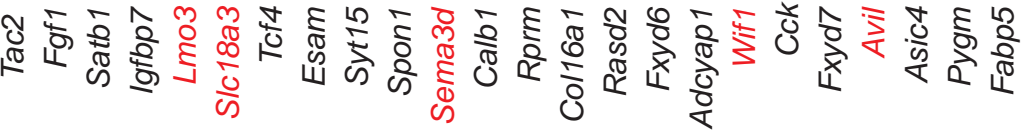


Figure 3 bioRxiv preprint doi: https://doi.org/10.1101/743401; this version posted August 21, 2019. The copyright holder for this prepri certified by peer review) is the author/funder, who has granted bioRxiv a license to display the preprint in perpetuity. It is mad

A

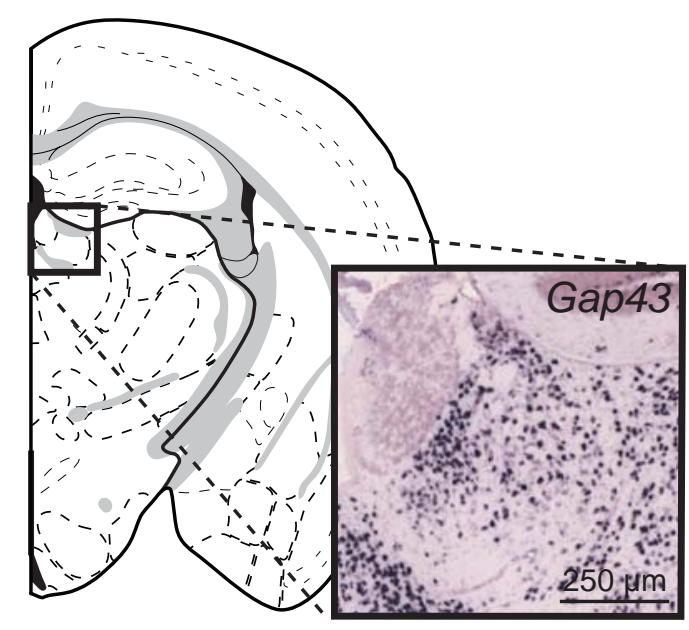
aBC-BY-NC-ND 4.0 International license.

C

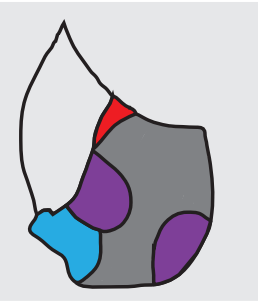

D

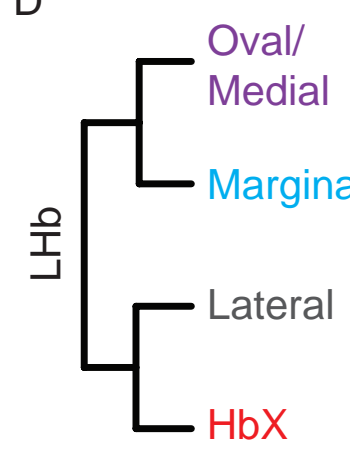

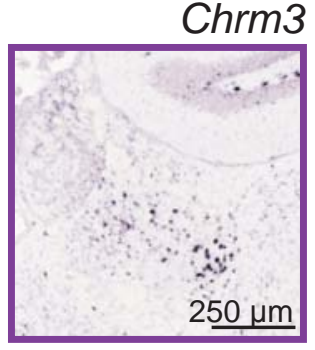

Oval/Medial

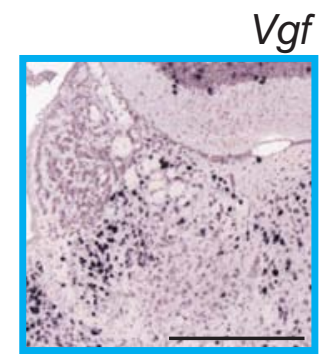

Marginal
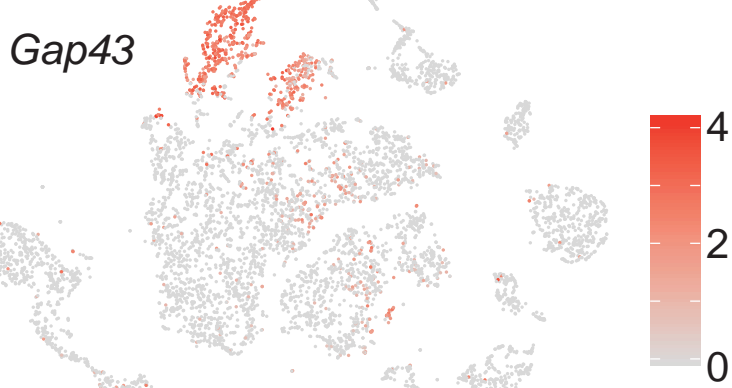

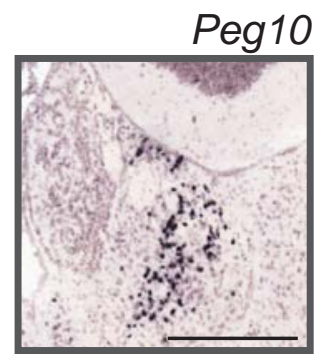

Lateral

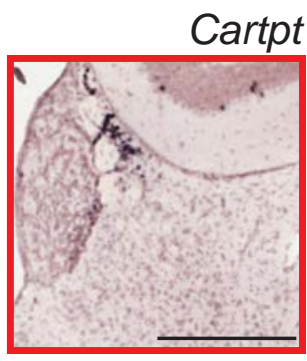

$\mathrm{HbX}$

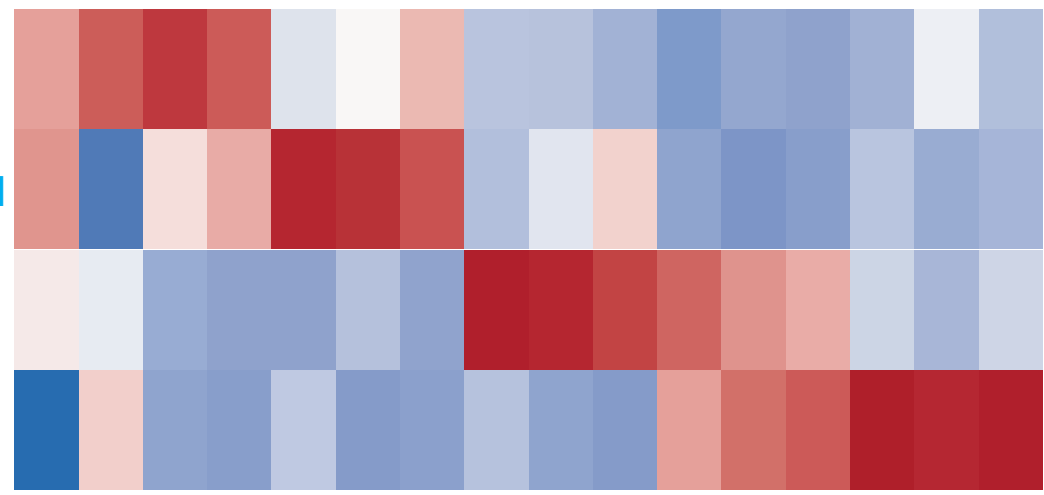

Mean Z-Scored Expression

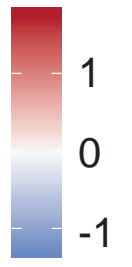

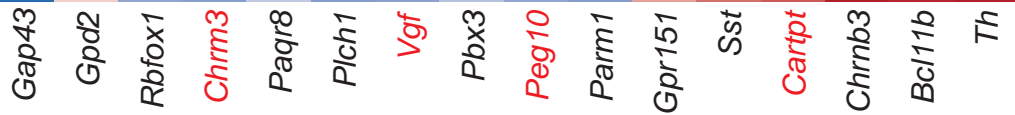


Figure 4 bioRxiv preprint doi: https://doi.org/10.1101/743401; this version posted August 21, 2019. The copyright holder for this prepri

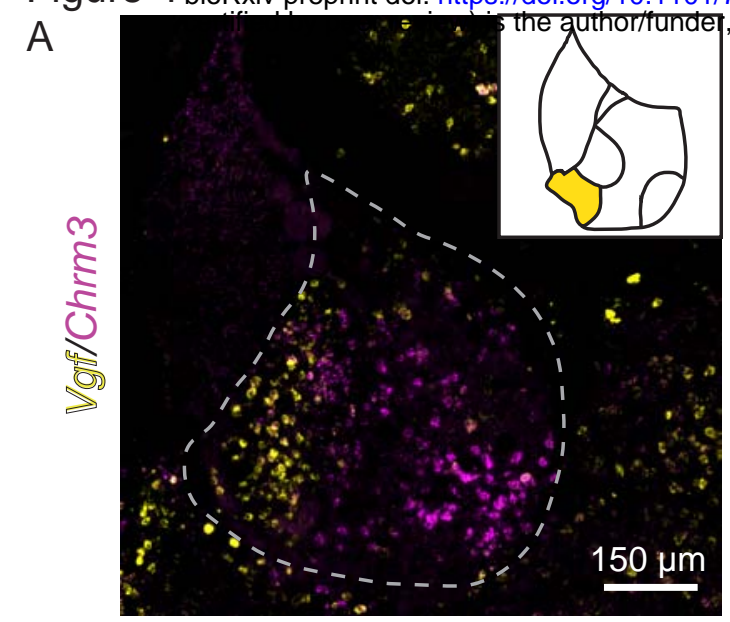
aCC-BY-NC-ND 1 international license.
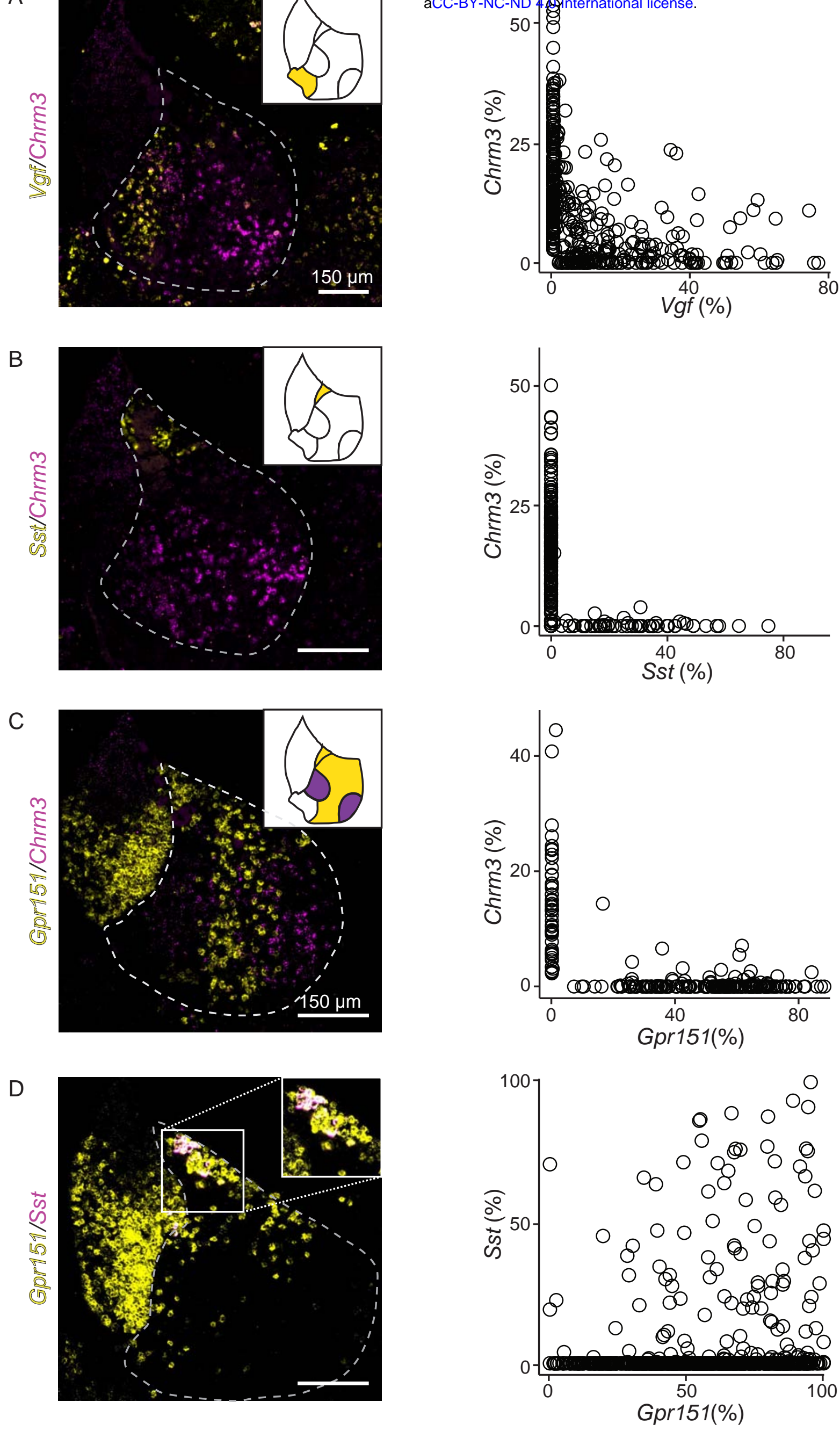
Figure 5 bioRxiv preprint doi: https://doi.org/10.1101/743401; this version posted Aug

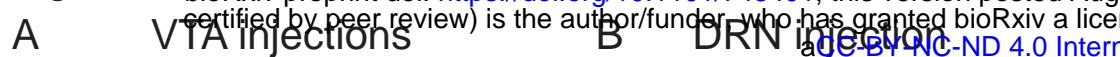
EnvA-RbV-GFP
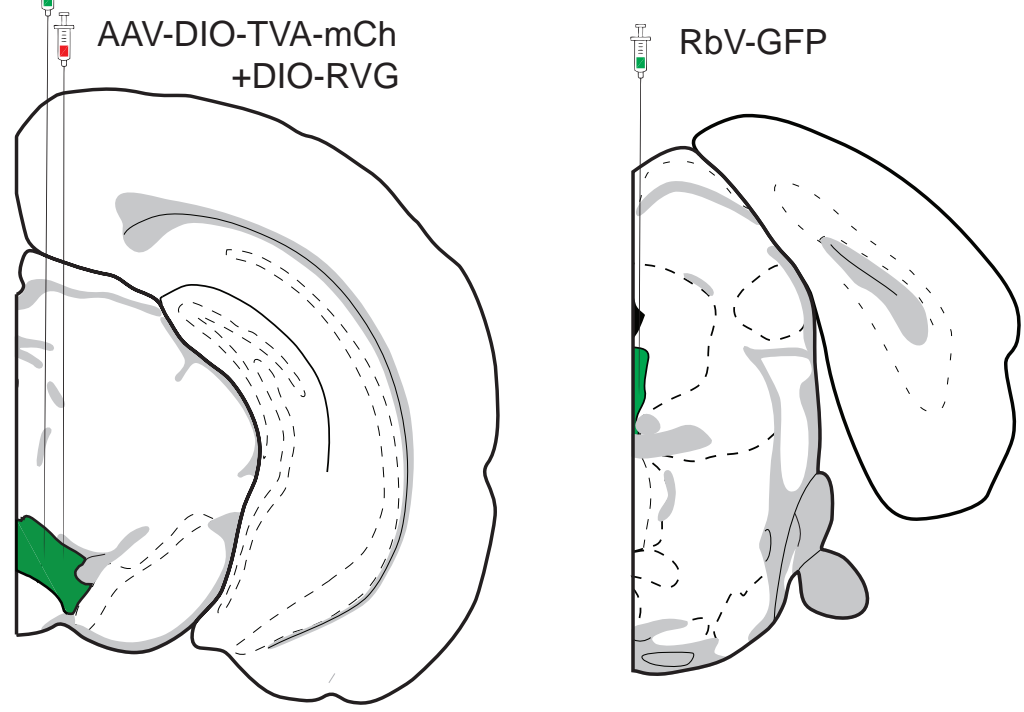

VGAT-IRES-Cre or DAT-IRES-Cre

C

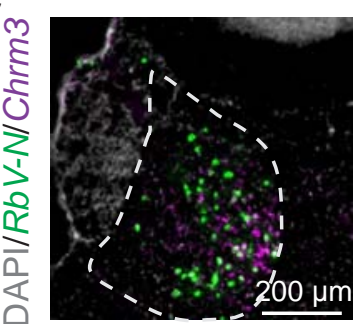

VGAT-IRES-Cre VTA

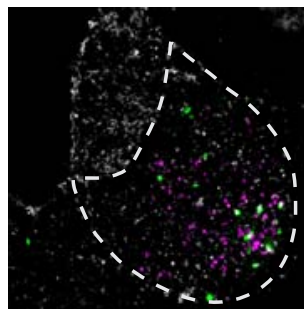

DAT-IRES-Cre VTA

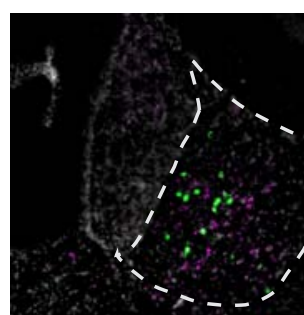

DRN

D
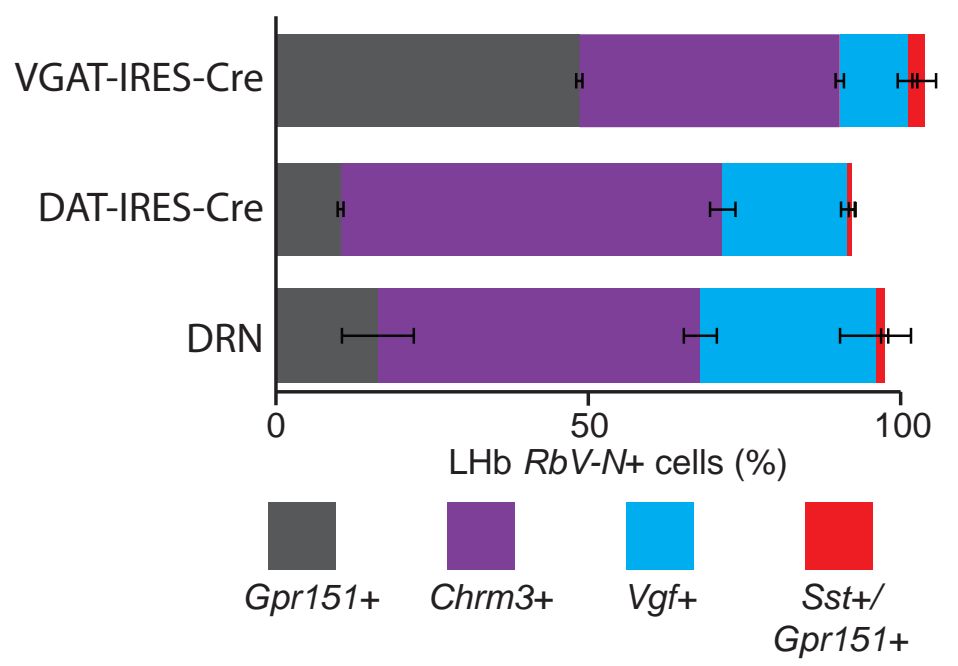